\title{
REVERTIR LA FUNCIÓN URBANÍSTICA PROPUESTAS-ENSAYOS PARA LA CIUDAD DE SEVILLA: EL PLAN
}

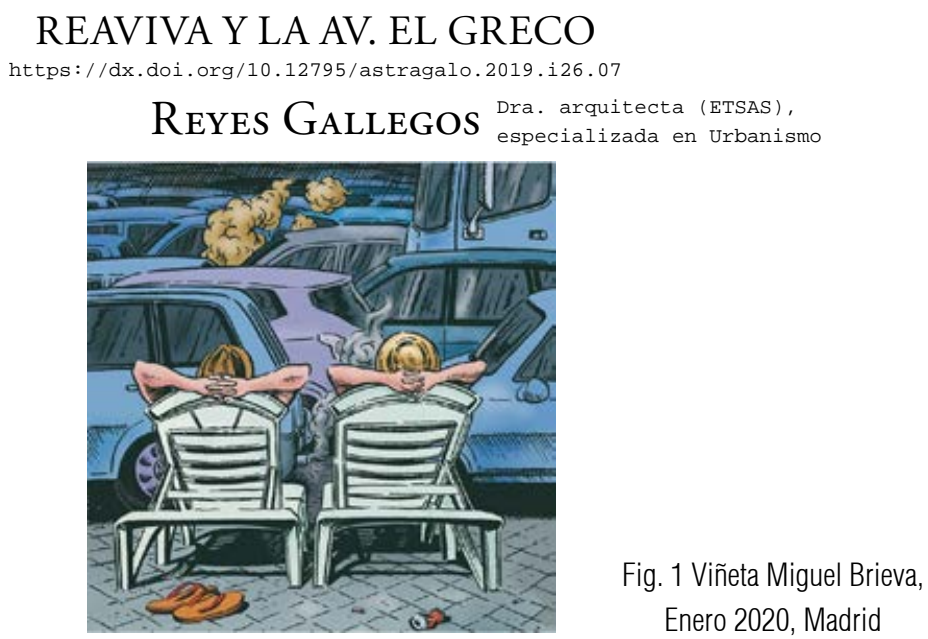

\section{ESTADO DE LA CUESTIÓN: UNA NECESIDAD, UN COMPROMISO.}

El urbanismo envuelve y determina nuestras vidas cotidianas. Cómo gestionamos los recursos, cómo nos movemos y vivimos la ciudad nos define como personas y como comunidad.

Sin embargo, "hace años que las bases de la habitabilidad moderna son cuestionadas por las interrogantes introducidas por el cambio climático que amenaza las condiciones básicas para la subsistencia de la vida humana en el planeta Tierra. Los modos de ocupación del territorio, respondiendo a criterios meramente económicos o funcionales, han sobrepasado el frágil y necesario equilibrio entre el desarrollo humano y el medio ambiente. El urbanismo que atendía a las lógicas del mercado en exclusiva, ha participado de un consumo de suelo desaforado y una generación desenfrenada de residuos tóxicos, que se suma a la devaluación del espacio público de nuestras ciudades hasta llevarlo a lo residual, expulsando a las personas y su posibilidad de convivencia" ${ }^{1}$. En la actualidad, la superficie de asfalto dedicada al vehículo motorizado ocupa más del $50 \%$ del espacio público; un soporte impermeable y emisor de calor, que impide la posibilidad de que las aguas de lluvia vuelvan a su cauce natural, además de no ser reutilizadas para el riego, por lo que mantener un espacio verde saludable y de calidad es cada vez más ingobernable. Por su parte, los recursos públicos se han privatizado cada vez más para pasar a ser gestionados y consumidos desde la individualidad, siendo del todo ineficaces.

Si bien la crisis inmobiliaria sirvió para tomar conciencia de que el planeamiento de la ciudad debía atender al medio ambiente, como

1 Fragmento de la introducción del Estudio Ciudad saludable, Emasesa, 2017. Félix de la Iglesia. 
lo reflejan las distintas leyes y normativas que inciden en el planeamiento general (Ley del Suelo, POTAS...), la gestión de las mismas a través de reglamentos y recomendaciones ha producido un desencuentro preocupante entre la teoría y su praxis. Desde esta perspectiva, se están abordando propuestas/ensayos para la ciudad de Sevilla, que sirvan para comprobar que, efectivamente, se puede revertir la función urbanística capaz de transformar la configuración del espacio público de modo que ponga la vida en el centro.

La ciudad como organismo vivo que es, solicita una respuesta que revierta la dinámica urbanizadora de las últimas décadas hacia soluciones que regeneren, oxigenen y devuelvan el ciclo natural a la tierra: no existe un Planeta $B$, es ahora o nunca el momento de sustituir lo funcional por lo metabólico, lo productivo por lo reproductivo; el capital por la vida.

Con el convencimiento de que la función urbanística puede dar respuesta a las agresiones ambientales de la ciudad contemporánea (mediante un modelo saludable de movilidad; la creación de anillos verdes o pulmones, que tienen un efecto transmisor y regenerador del entorno; interviniendo en el espacio público urbano determinado por factores como la temperatura, el uso de materiales nobles, el drenaje sostenible, la disminución de radiación solar, el aumento de vegetación, la existencia de agua, la escala humana, la densidad, la percepción de seguridad, las condiciones acústicas, el color o la ergonomía, la calidad del aire, entre otros. -todos ellos parámetros interconectados-), y a partir de un conocimiento acumulado de otras experiencias previas -al nivel tanto global como local en la ciudad de Sevilla (como es la participación en el PGOU y Plan Especial Polí- gono Sur)- tuvimos la oportunidad de trabajar en las propuestas-ensayos que aquí se relatan.

Trabajar en el territorio de Sevilla nos ha permitido partir de uno de los modelos que se demuestran como más sostenibles: una ciudad compacta, mediterránea y cohesionada socialmente en cuanto a la complejidad de sus $u^{u}{ }^{2}$. Sin embargo, la realidad actual no termina por desarrollar dicho modelo ni salvar las evidentes disfunciones en el hacer cotidiano de sus habitantes, en concreto, en la vivencia de sus espacios de convivencia (con mayor devaluación aún en los barrios de la periferia). La movilidad no resuelta a cuenta de la dispersión de los barrios dormitorios del Área Metropolitana, con una dependencia notable de la ciudad centro como fuente de producción y servicios, hacen de los espacios libres meros canales de tráfico de difícil ocupación y valoración en muchos casos.

Como alternativa, nace el Plan Reaviva, un plan de Microactuaciones de mejora urbana de los espacios públicos existentes en los 11 distritos de Sevilla, (2016-2020), que actúa como instrumento de rehabilitación y reactivación urbana desde la ecología, y diseñado desde una perspectiva de género ${ }^{3}$ y en base a principios como la equidad social y equidistribución de recursos públicos a todo el territorio. El resultado, tras un extenso trabajo de campo y análisis (rutas, encuestas y análisis de información técnica y demandas vecinales históricas, estudio de prácticas nacionales e internacionales) son más de cien actuaciones estructuradas en

2 Así se recoge, como estrategia en el Plan Especial de Indicadores de Sostenibilidad Ambiental de la Actividad Urbanística de Sevilla (2008).

3 "Flânerie es femenino", Hacia una arquitectura de los cuidados. 
4 bloques o estrategias de actuación, de forma que cada microactuación, por pequeña que sea, tiene identidad local y metropolitana:

E1. Activadores de Sistemas generales de espacios libres.

Actuaciones que tratan de incorporar la naturaleza a la ciudad, poniendo en valor la periferia, mediante acciones como itinerarios, accesos o señalética, que activen el sistema general de espacios libres (aprovechando los recursos de los que dispone la ciudad de Sevilla: Río, Puerto, Huertos, Parques metropolitanos, etc.) y actuaciones que frenen la contaminación de los márgenes de la ciudad (residuos y otras agresiones ambientales). Apuestan por un turismo alternativo, basado en conocer, disfrutar y participar de la conservación de los recursos

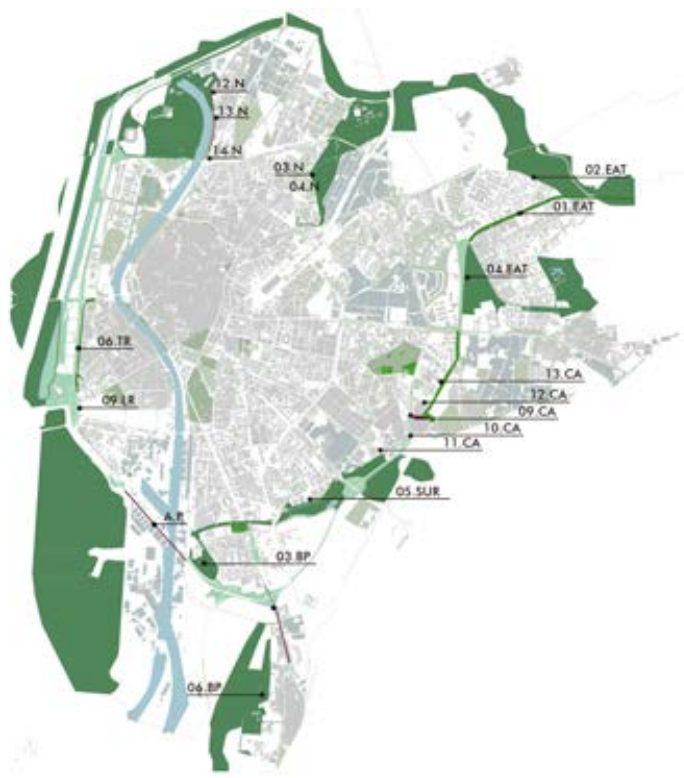

naturales y culturales de las ciudades, saliendo de los muros de ésta (Leer: Vitoria-Gasteiz: Ciudad-naturaleza).

E2. Reactivación de grandes "conectores" de barrios.

Actuaciones que conectan barrios y realidades activando bulevares, avenidas y rondas urbanas, que hacen de límites y fracturas, transformándolas en una red de corredores verdes e itinerarios saludables. Se apuesta por una movilidad sostenible (reduciendo la superficie para el vehículo privado motorizado, garantizando la eficacia del transporte público y priorizando al peatón), hacia una ciudad más cohesionada y segura; y regenerando a su paso espacios abandonados o infrautilizados, mejorando su calidad ambiental y paisajística desde una

Fig. 2 y 3. Esquemas de las estrategias propuestas en el Plan Reaviva. Fuente: Elaboración propia.

E1. Activadores del Sistema General de espacios libres, Plan Reaviva, Sevilla (izquierda) / E2. Red de "Conectores de barrios", Plan Reaviva, Sevilla (derecha) 
perspectiva ecológica. (Leer: Paseo de St Joan, nuevo corredor verde).

E3. Proyectos de accesibilidad.

Actuaciones por la accesibilidad de todas las personas -y generaciones- a todos los espacios y equipamientos públicos. Hacer de la ciudad una ciudad inclusiva y segura mediante itinerarios y actuaciones en acerados y cruces, pasos de peatones, rampas, barandillas, caminos escolares y seguros, y restricciones al coche, eliminando obstáculos y construyendo hacia "un urbanismo para las personas".

E4. Proyectos de rehabilitación de plazas y/o pequeños parques.

Actuaciones que recualifican paisajística y ambientalmente los entornos de proximidad, soporte fundamental para los cuidados y la convivencia entre vecinos. Estas actuaciones mejoran la habitabilidad, aprovechan los recursos existentes, reciclan y renuevan las instalaciones obsoletas y mejoran la eficacia de la inversión coordinando las diversas áreas administrativas locales. (En la medida de lo posible, generar economía y empleo local en la ejecución y mantenimiento de las actuaciones).

En cada actuación se proponen distintas líneas de trabajo, pero con un denominador común: un proceso colectivo de "co-diseño" (con grados de participación/colaboración diferentes, en función de la escala, la urgencia o contexto).

"Desde la voluntad de evolucionar en los modos de gestionar la ciudad y las comunidades del futuro, se apostó

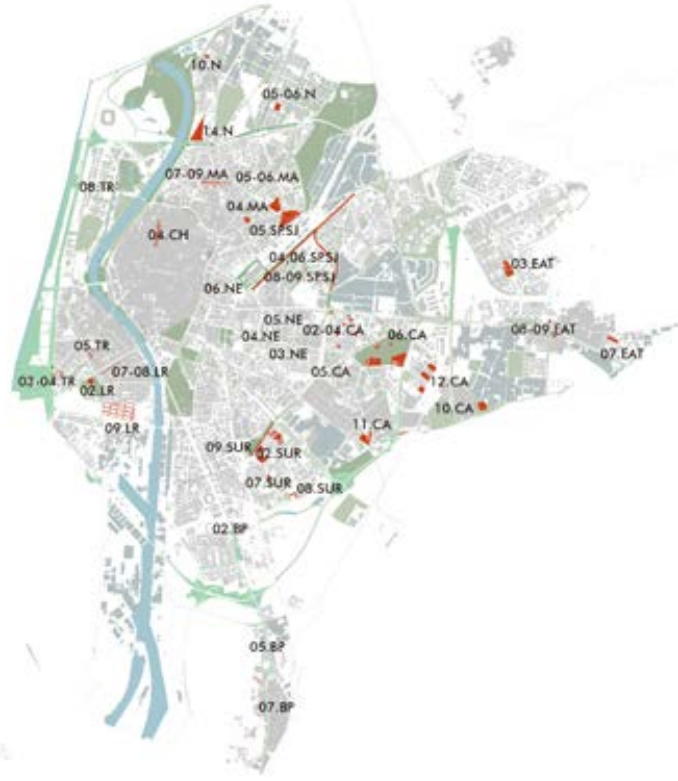

Fig. 4 y 5. Esquemas de las estrategias propuestas en el Plan Reaviva. Fuente: Elaboración propia.

E3. Proyectos de accesibilidad (izquierda) / E4. Proyectos de rehabilitación de plazas y/o pequeños parques (derecha) 
por introducir cambios metodológicos en los procesos de diseño urbano a través del Plan Reaviva. Éste es pionero en la ciudad de Sevilla y relevante en varios aspectos: la incorporación de la ciudadanía en la toma de decisiones a través de modelos participativos activos; la introducción de nuevas conductas técnicas que han posibilitado el trabajo transversal entre las diferentes áreas del Ayuntamiento; y la coordinación de éstas con los técnicos, mediadores, entidades y vecinos. Así como la posibilidad de una ejecución directa en casos concretos, ahorrando trámites urbanísticos.

La llamada "Metodología Reviva", como herramienta, ha tomado sentido al implementarse sobre realidades particulares, dado que cada microactuación posee su naturaleza característica. Por ello, ha resultado fundamental que los protocolos del proceso participativo hayan sido aplicados de manera abierta y flexible".

(Extracto del Informe Plan Reaviva, Noviembre 2019) / Fotografía: Plaza del Olivo, Distrito Macarena, Sevilla.

El modelo de ciudad sobre el que se quiere avanzar debe estar claro desde el inicio: es muy importante que el proceso participativo esté guiado y estructurado de forma que la aportación de todas las partes (conocimiento técnico + desde la experiencia) tenga unos objetivos claros. En cuanto a la Metodología desarrollada en los procesos de codiseño de las actuaciones, se ha ido adaptando a cada lugar y contexto, aunque manteniendo siempre unas estrategias concretas, como el uso de canales diversos para su comunicación y difusión (digitales y analógicos) dirigidos a todas las generaciones; y la búsqueda de alianzas y colaboración entre las distintas áreas administrativas de competencia y ciudadanos organizados o a título individual: expertos, académicos, comerciantes, políticos, vecinos, representantes de entidades, etc. A los distintos agentes urbanos convocados, se le han ido sumando asociaciones, ampas, universidades o plataformas activas y vinculadas a cada espacio y atraídas por la convocatoria pública. Este es uno de los motivos por el que, aunque la metodología se ha ido modificando en cada caso, siempre hemos mantenido la importancia de reunirnos en el lugar de la futura actuación para hacerlo lo más abierto posible: las reuniones de trabajo in situ ayudan a que se unan ciudadanos no organizados, además de favorecer a una actitud constructiva, de escucha y empatía, lo que promueve una evidente evolución en términos de coherencia, transparencia y eficacia institucional para dar soluciones a necesidades ambientales y sociales de nuestras ciudades. En los procesos llevados a cabo desde 2017 hasta hoy hemos podido comprobar el potencial que tienen las comunidades locales y las inteligencias ciudadanas juntas para recuperar la ciudad.

Uno de los ejemplos ha sido el del Paseo de Bonanza (antes sin nombre). Esta calle tenía tratamiento de "trasera" de la Calle Tarfia, muy cerca de la Escuela de Arquitectura de Sevilla, y un importante eje peatonal para sus vecinos. A pesar de su interesante ubicación, su atractiva perspectiva y escala, y el arbolado de gran porte existente, el mal estado del pavimento (completamente levantado por las ramas de los árboles -asfixiados en alcorques que no llegaban al 
metro cuadrado-) y los escasos pasos peatones que la conectan con el Campus Reina Mercedes y con Páez de Rivera, dificultaban la accesibilidad y el paseo de los vecinos, en su mayoría antiguos trabajadores del puerto, hoy jubilados. Así que el primero de los objetivos fue ensanchar los alcorques, incluso unir varios en amplias zonas ajardinadas, ya que la sección de la calle permitía dejar paseos accesibles alrededor de éstos. Esta experiencia reúne varios aspectos fundamentales para el análisis de los avances realizados, y de las dificultades. Por un lado, nos ha delatado que el urbanismo actual no

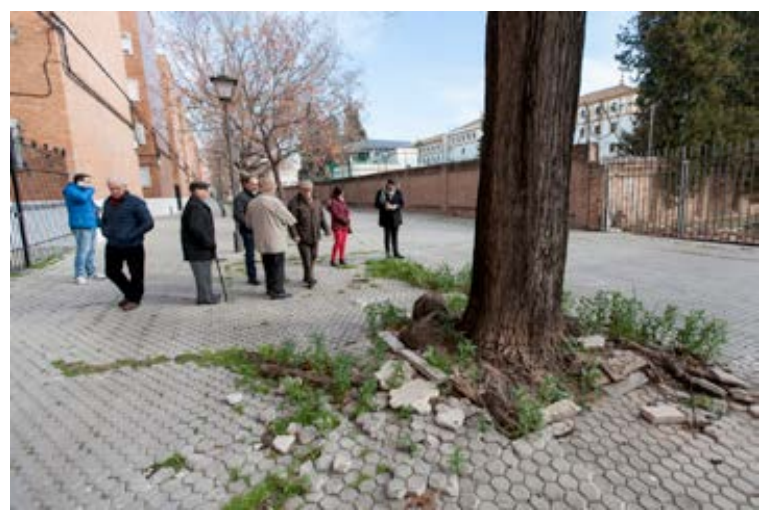

Fig. 6. Foto del primer encuentro con los vecinos del nuevo Paseo Bonanza, Febrero 2018 está formulado para un proceso donde, varios agentes implicados quieren ponerse a trabajar juntos para, con los mínimos recursos, obtener la solución más óptima de un problema urbano que llevaba tiempo sin resolverse.

A pesar de que la ciudad es un organismo vivo y cambiante, la división de competencias crean a veces un conflicto a la hora de plantear una nueva delimitación, como e el caso de los alcorques, que alteraban notablemente la superficie de "suelo duro" (competencia de la Gerencia de urbanismo) y "suelo mixto y blando" (competencia de Parques y jardines). Uno de los retos para el futuro del Urbanismo es la flexibilidad y coordinación de áreas y servicios municipales con competencia en la gestión del espacio urbano: Servicio de Parques y Jardines, IED, LIPASAM, EMASESA, Movilidad, etc. Y no sólo porque ahorraríamos muchísimos recursos, sino porque los tiempos del urbanismo serían mucho más cortos, evitando trámites de licitación y contratación eternos. Afortunadamente, este obstáculo se pudo salvar porque el Plan Reaviva -al no ser un documento oficial- no responde a normativas ni ordenanzas de planeamiento (que en lo que respecta al espacio público, limitan más que favorecerlo),

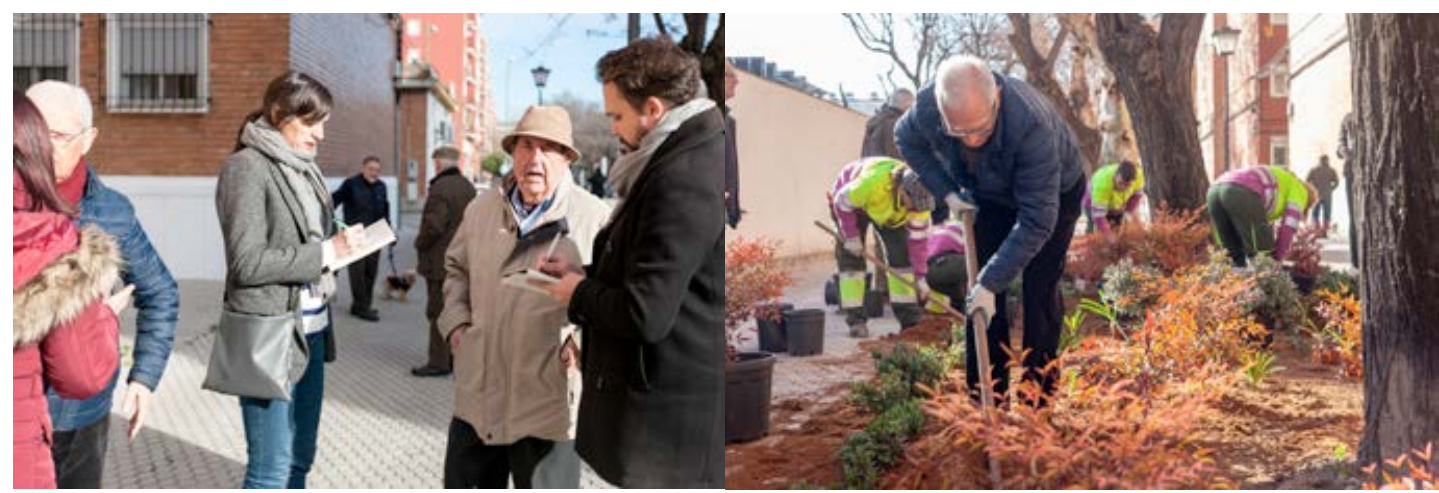

Fig. 7 y 8. Plantación colaborativa (participativa) de alcorques, coordinado con Parques y jardines 
y porque cuenta con la implicación de los técnicos responsables desde el inicio del proceso, cosa que provoca que este tipo de iniciativas sea tan frágil como que dependa de la suerte de la voluntad de los administradores.

El segundo objetivo de esta microactuación fue el de realizar una plantación colectiva con la comunidad de vecinos -decidiendo con ellos el tipo de vegetación-, con la Escuela de Arquitectura y los operarios de Parques y Jardines. De nuevo se logró gracias a las voluntades de todas las partes, sin que pudiéramos formalizar ninguna colaboración por temor al aplazamiento que ello supondría. En este sentido, sería muy interesante abrir líneas de colaboración con otros agentes privados y colectivos, Instituciones Académica, Área de Juventud, Deporte o Servicios Sociales, para que se repartan competencias e inversiones de las actuaciones en relación a las acciones, incluso al mobiliario, mantenimiento, etc.

Estos alcorques "ensanchados" serían posteriormente adoptados y dependientes de un futuro mantenimiento compartido entre los agentes. Los vecinos se hicieron "corresponsables" de las labores de riego, poda y vigilancia. Y así sigue siendo, pero el proyecto para la acometida de riego aún está en la Gerencia de Urbanismo esperando ser tramitado (a expensas de una aprobación del presupuesto), por lo que de nuevo los plazos inherentes al urbanismo actual juegan en contra, y pueden provocar que los nuevos jardines-alcorques se sequen.

Los vecinos deben conocer los tiempos que requiere la redacción de los proyectos, la licitación, aprobación de presupuesto, etc. hasta concluir en el final de obras. Es necesario dar a conocer esta información desde el inicio del proceso, así como seleccionar las actuaciones más viables en los organismos competentes en materia de transformación urbana. Aún quedan algunas cuestiones que conciliar en términos, por ejemplo, de reutilización de recursos públicos, o de prioridades relacionadas con la Movilidad, así como la dificultad encontrada a la hora de implementar y/o tramitar actuaciones de un simple "Cambio de uso" a "bajo coste" que dé respuestas rápidas a conflictos urbanos reales que, van más rápidos que los plazos burocráticos.

En todas las propuestas los vecinos ven reflejadas de forma directa las decisiones tomadas según sus intereses personales o colectivos respecto a su realidad cotidiana. En el ejemplo de Tarfia, el hecho de que todos los agentes intervinientes se hayan movilizado y puesto "manos a la obra" y que las distintas partes y generaciones se hayan unido para un fin común, ha sido fruto de la escucha, búsqueda de consenso y respeto a todas las solicitudes. Este proceso se inicia desde las primeras reuniones, en las que entregamos un primer documento de diagnóstico a partir del que se comienza a discutir. En las reuniones consecutivas, llevamos paneles donde reflejamos las conclusiones y propuestas de las reuniones trasladadas al plano, con nombres y apellidos de todos los participantes. Además, mostramos muchas imágenes de referencia para una mejor comprensión de las propuestas. La devolución a los técnicos de la Gerencia de urbanismo la hacemos con suficiente detalle, y, afortunadamente, el compromiso como consultoría nos permite comprobar que el proyecto que se licite en los próximos meses se adecúa al proyecto que ha sido codiseñado con los vecinos.

Esto, a veces, conlleva actuaciones no imaginadas por los técnicos: además de las dificultades burocráticas que todos estos proce- 
sos conllevan, nos ha sorprendido y preocupado algunas de las peticiones o quejas comunes a todos los grupos motores, concretamente las de solicitar vallas y más control policial, así como soluciones que requieren el mínimo compromiso cívico, de convivencia y de mantenimiento. Con frecuencia hemos tenido que contextualizar las actuaciones del Plan Reaviva no sólo desde los objetivos y criterios, sino desde la negación a algunas actuaciones ${ }^{4}$ :

- NO poner más vallas

- NO poner césped artificial

- NO quitar bancos

- NO quitar canastas

- NO hormigonar alcorques

- NO reducir la superficie blanda, sino aumentarla (ídem para suelo permeable/impermeable; materiales nobles/no nobles; naturales/artificiales)

- NO acotar más los espacios de los perros

- NO más plazas de aparcamiento en superficie de suelo público

- NO poner cámaras de video vigilancia en el espacio público

- NO homogeneizar más los espacios (texturas, materiales, colores, árboles...)

- NO separar los espacios para niños y mayores

Sin embargo, tras las primeras sesiones de trabajo e información, siempre hemos conseguido concluir con un clima más constructivo, analizando la situación y buscando soluciones a estas problemáticas. Es importante ahondar sobre el porqué de cada uno de estos "NOES" y las alternativas a los mismos, por una necesaria reeducación en el espacio público, dirigido a usuarios, técnicos y gestores de lo público. Queda mucho por hacer para acabar con el exceso de prejuicios (muchos de ellos generados por las dificultades en la gestión pública) y la autolimitación que generan éstos, responsables, con frecuencia, de que no valoremos la importancia del espacio público como un espacio de libertad que tenemos que recuperar entre todos. Encontrar la solución a los "NOES" teniendo en cuenta la realidad de los conflictos de la ciudad contemporánea que conocemos gracias a que los grupos motores que participan del Proceso del Plan Reaviva nos lo relatan a diario (y que dista mucho de la modélica ciudad de Jacobs) es el reto del urbanismo que quiera apostar por una resignificación de los espacios públicos y por una reeducación ciudadana hacia la libertad.

Ejemplos como éste, llevados a cabo con el Plan Reaviva, han generado numerosos cambios en la manera de concebir y aproximarnos a la gestión urbana, así como la concepción en los procesos y el diseño de los proyectos. Estos cambios se han producido no sólo en la forma de trabajar del Equipo Reaviva, sino también en todos los técnicos implicados, tanto de la propia Gerencia de Urbanismo de Sevilla como en los diversos Distritos, algo que nos parece un enorme avance. En los procesos llevados a cabo hasta hoy han participado gran diversidad de agentes, cada uno de ellos siente y vive la ciudad de una determinada manera y tiene unos objetivos e intereses diferentes. En el plan hemos aprendido a mediar, a exponer situaciones, en ocasiones enfrentadas, y a propiciar debates en los que las comunidades han alcanzado objetivos comunes.

4 "Los once NOES" del Plan Reaviva 
TRABAJAR CON FRAGMENTOS PARA CONSTRUIR UN SENTIDO COMÚN

Como se ha dicho ya, las estrategias del Plan Reaviva derivaron en más de un centenar de propuestas (actuaciones en movilidad, accesibilidad, iluminación, vegetación, mejora de calles, parques, plazas o creación de caminos escolares seguros) distribuidas en los 11 distritos, que se dibujaban una serie de recorridos (y éstos a su vez ecotonos) que permiten trabajar con fragmentos para construir un sentido común: una gran red metropolitana a la que no sería difícil aspirar en Sevilla coordinando iniciativas que ya existen; como el Plan de huertos urbanos, el Plan Reaviva, el Plan cultura y el Plan bici. En ese futuro, se descentralizan los recursos, y se refuerza la ecología, los cuidados y la equidad, con espacios públicos para la vida y con nuevos modelos de desplazamiento accesibles para todos -y menos contaminantes-, como hizo Lerner en Curitiba que, por ejemplo, creó un nuevo sistema de transporte público que conectaba los parques, los colegios y las bibliotecas municipales de todos los barrios.

Decía Enrique Peñalosa, exalcalde de Bogotá, que la cultura de una ciudad podía medirse en los modos de desplazamiento, y que una ciudad avanzada es aquélla en la que los ricos también se mueven en bici y en transporte público. En Nueva York, el simple corte de una calle, convirtió Broadway y Times Square en cines de verano al aire libre. Una señalética en el suelo permite que las iniciativas de Caminos escolares seguros sean la mejor práctica en materia de accesibilidad y educación. En Noruega, la plaza Dreamhammar, pasó de ser un gran aparcamiento al aire libre a ser el espacio de encuentro intercultural entre diversas comunidades por medio de una intervención de arte urbano. Ejemplos como el anillo verde de Vitoria Gasteiz, incorporan la naturaleza en la ciudad desde sus grandes parques y huertos periurbanos que entran hasta las rondas históricas pasando por grandes equipamientos culturales y pequeñas infraestructuras de barrio.
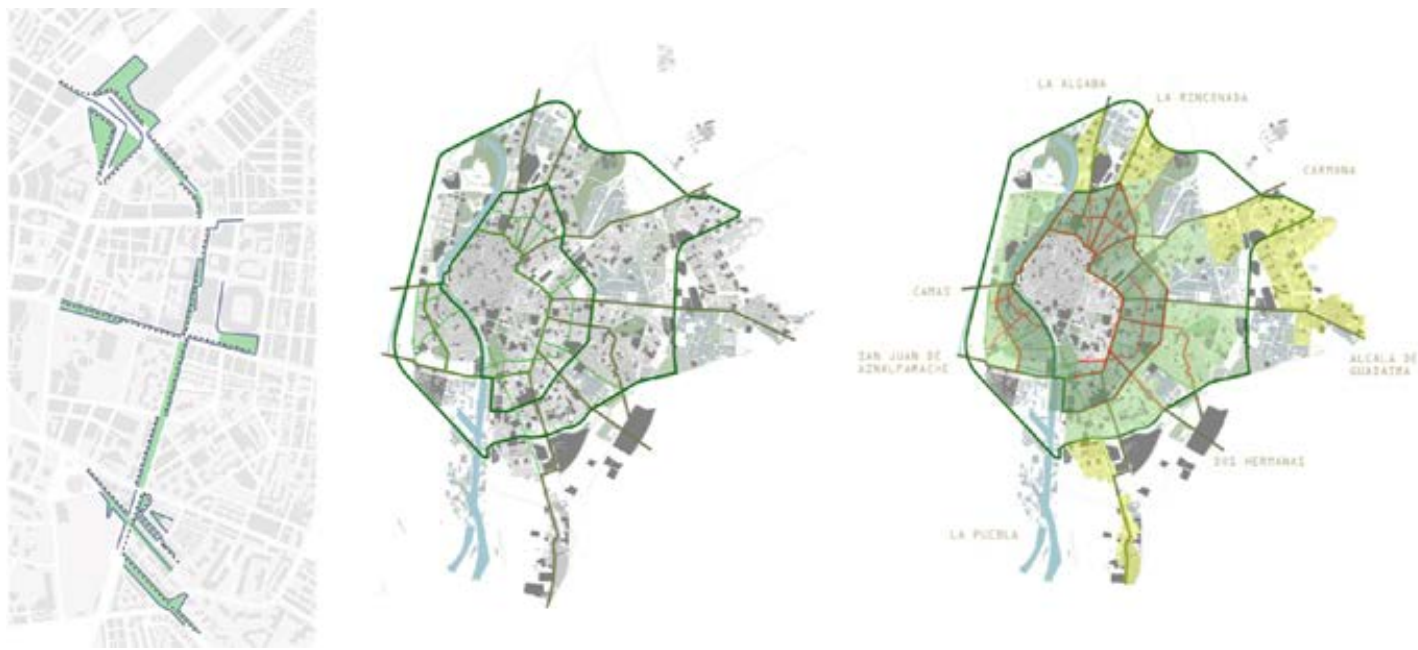

Fig. 9. Esquemas de la Red propuesta de corredores verdes Sevilla 2030. Propuesta realizada para el estudio de Ciudad saludable, Emasesa, 2017) 

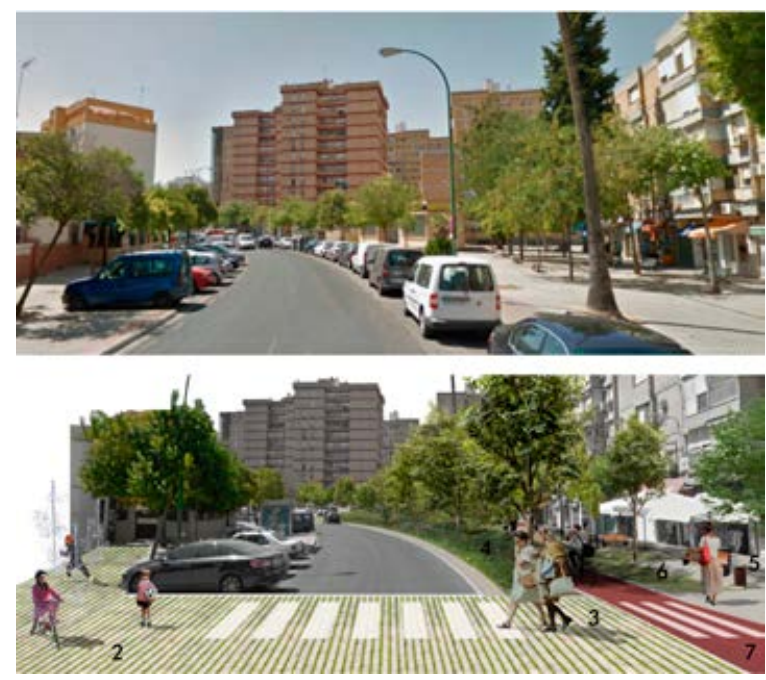

Fig. 10. (Fotomontaje Antes y después de la Av. Gavilanes, Sevilla. Propuesta realizada para el estudio de Ciudad saludable, Emasesa, 2017)
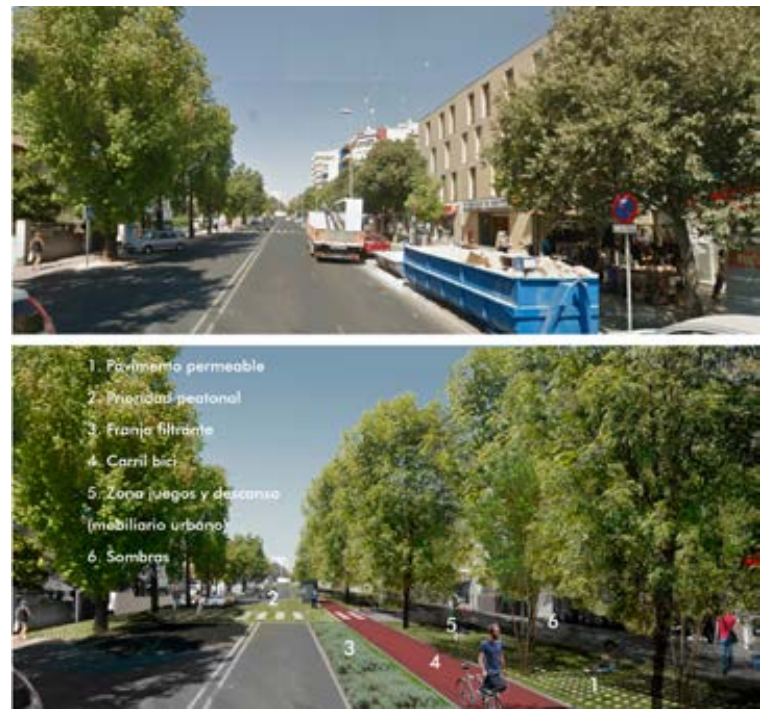

Fig. 11. (Fotomontaje antes y después dela Av. Marqués de Pickman, Sevilla. Propuesta realizada para el estudio de Ciudad saludable, Emasesa, 2017)
Entre los "conectores" o corredores verdes propuestos desde una Estrategia metropolitana para Sevilla, se encuentran Avenidas como El Greco (San Pablo), Cruz Roja (Macarena), Luis Montoto, Marqués de Pickman (Nervión), Av. La Paz, Gavilanes (Sur), o la Av. de la Mujer Trabajadora (Polígono Norte), entre otras. El estudio de cada una de ellas se ha ido canalizando en diferentes vías. Esto aporta una visión de futuro para una Sevilla como ciudad conectada por un transporte público eficaz y corredores verdes como soportes estratégicos que salen de la muralla para recuperar los valores e identidades de todos sus barrios, activando el patrimonio paisajístico y cultural de cada barrio.

De forma distinta a como se han canalizado algunas de las actuaciones procedentes del Plan de estrategias de mejora urbana Reaviva ${ }^{5}$ (y otras que esperan ser atendidas), la regeneración de la Avenida de El Greco, en el distrito San Pablo - Santa Justa de Sevilla, se inscribió en el marco del Proyecto Ciudad Saludable.

\section{PROYECTO CIUDAD SALUDABLE}

Con base en los objetivos planteados para el ámbito de Sevilla y en la revisión y análisis de los documentos y estrategias utilizadas en el Plan Reaviva, y en el Marco de la Estrategia Andaluza de Sostenibilidad Urbana ${ }^{6}$, desde EMASESA se plantea la necesidad de abordar un proyecto innovador de investigación e Intervención en

5 (Ver otros ejemplos ejecutados: Plan Reaviva)

6 El marco general de la Estrategia Andaluza de Sostenibilidad Urbana, de entre cuyos objetivos, propuestas y líneas de actuación destacamos las siguientes:

- La política urbana en relación al agua gira alrededor de la consideración de su uso en un ciclo integral, que 
comprenden todas las fases de su utilización, desde la captación de caudales hasta la devolución al medio natural en condiciones satisfactorias de calidad.

- Realizar una gestión integral sostenible del ciclo urbano del agua (captación, transporte, almacenamiento, potabilización, distribución, consumo, saneamiento, depuración, reutilización y vertido).

- Fomentar el ahorro y la eficiencia en el uso del agua a través de mecanismos como la gestión conjunta entre los grandes usuarios (agricultura, industria y ciudad), la reutilización de agua depurada y el aprovechamiento, en su caso, del agua de lluvia. A este respecto debe consolidarse a mejora de sistemas de tratamiento de aguas residuales urbanas e industriales

- Recuperar los escenarios sociales del agua como parte esencial del patrimonio cultural y de la memoria colectiva.

- El uso que del recurso se hace se ajustará a criterios de eficiencia en un modelo de ciudad que atiende a criterios de sostenibilidad, adaptado a las condiciones climáticas y a los condicionantes locales. La devolución del recurso, después de ser usado, se efectuará en condiciones de calidad aceptables como resultado de la adopción de tecnologías de depuración con tecnologías adecuadas y de coste ajustado y atendiendo también a criterios de ahorro, eficiencia, recuperación y valorización energética.

- Renaturalizar, en la medida de lo posible, los cuerpos de agua urbanos en consonancia con el desarrollo de las redes verdes.

- Crear infraestructuras para la distribución y consumo de aguas residuales tratadas destinadas a campos de golf, sector agropecuario, riego de zonas verdes, baldeos, determinadas actividades industriales, etc.

- Implantar, de forma progresiva hasta su generalización, las mejores soluciones tecnológicas disponibles de eficiencia en la utilización, con el fin de rebajar los estándares de consumo.

- Articular medidas para que los nuevos desarrollos urbanos abastezcan sus consumos por encima de la dotación básica personal, mediante el uso de recursos alternativos: pluviales, subterráneas locales, grises, recicladas, ...

- Desarrollar programas de eficiencia en la jardinería, potenciando la implantación de especies xerófitas propias del clima mediterráneo.

- Implantar medidas para mantener índices elevados de permeabilidad del suelo y de la capacidad de infiltración, así como otras que deriven las aguas relación al Ciclo Integral del Agua en el ámbito urbano, con los objetivos cercanos de presentar un documento de criterios y estrategias de intervención en el espacio público para así desarrollar un Proyecto Piloto que evaluar y desde el que plantear un conjunto de estrategias y protocolos trasladables a diversas situaciones urbanas de la ciudad de Sevilla y medios urbanos. Se plantea así el reto de redactar las bases urbanísticas que permitieran desarrollar un "Modelo de ciudad saludable, ecológica y social para Sevilla en el marco del Ciclo Integral del Agua, establecimiento de indicadores y elección de enclaves para experiencia piloto".

La complejidad del proyecto supondrá un avance decisivo en el proceso de constitución de una alternativa integrada y más receptiva a los problemas actuales de nuestros entornos urbanos y territoriales en el horizonte de una gestión equilibrada de la confrontación entre metabolismo urbano y eficiencia medioambiental. La materialidad urbana, entendida por la geografía actual como paisaje fundamento de cualquier proyecto urbano, y una nueva urbanidad posmetropolitana, con sus componentes físicos y culturales, serían el grado cero desde el que administrar tanto los procesos energéticos y comunicativos del metabolismo urbano, como su correcta y medida administración de manos de la cultura de la sostenibilidad.

Se revisan aquellos ya comprobados en muestras de distintos tejidos urbanos y que evalúan el grado de acomodación de la ciudad al

de primer lavado de las redes viarias con elevada contaminación hacia balsas de tormenta y/o las EDAR, evitando su infiltración en los acuíferos.

- Desarrollar programas de comunicación y participación para recuperar los escenarios sociales del agua urbana para preservar la memoria colectiva y el patrimonio cultural. 
modelo de ciudad más sostenible. En especial, los referentes al Plan Especial de Indicadores de Sostenibilidad Ambiental de la Actividad Urbanística de Sevilla (2008), dirigido por Salvador Rueda, para su revisión y actualización, priorizando según el interés y objeto del Proyecto Piloto, y considerando igualmente la incidencia de los Planes y Proyectos Estratégicos previstos:

- Movilidad (tranvía, red de carriles bici, red peatonal, regulación de los aparcamientos en superficie),

- Reducción del impacto ambiental de la contaminación y el ruido en las calles,

- Aumento de la calidad del espacio público en términos de accesibilidad,

- Aumento de habitabilidad del espacio público: accesibilidad, permeabilidad peatonal, presencia de vegetación, confort térmico y acústico, calidad del aire, seguridad.

El resultado de un extenso estudio logra condensar en 10 parámetros urbanos comunes e interconectados (y que se enuncian a continuación) que responden a los argumentos planteados, en relación con el urbanismo [y la participación] y en razón a los objetivos y el ámbito donde se desarrollarán los ensayos ${ }^{7}$. El primero de ellos (tras una puesta en común de criterios de EMASESA, la Gerencia de Urbanismo, y la Dirección General de Parques y Jardines del Ayuntamiento de Sevilla -y otras sinergias coyunturales inherentes al urbanismo: fondos europeos y autonómicos-) serán 800 metros longitudinales de la Avenida del Greco, en el Polígono San Pablo de Sevilla.

7 Jardines sin fronteras. Avenida El Greco, un nuevo concepto de ciudad: https://cutt.ly/myX2ckg

\section{CUANTIFICAR LA INTERVENCIÓN URBANA. AVENIDA EL GRECO}

Se incluyen a continuación tablas de algunos de los elementos de la Av. Del Greco que consideramos más relevantes cuando realizamos el estudio de la calidad ambiental y otros factores considerados en el diseño para su reurbanización. Concretamente los relacionados con la escala y visibilidad de la calle, la vegetación, los pavimentos y la presencia de agua. (En el Anexo 1 puede consultarse toda la relación de índice y subíndices cuantificados).

\section{1.- SIGNIFICACIÓN TERRITORIAL:}

Cercanía y conexión a un espacio libre de escala metropolitana.

Cohesión social y urbana. Impacto en el contexto urbano local o metropolitano. Nivel de afectación en el tejido urbano y social adyacente.

\section{Ej. Av. El Greco}

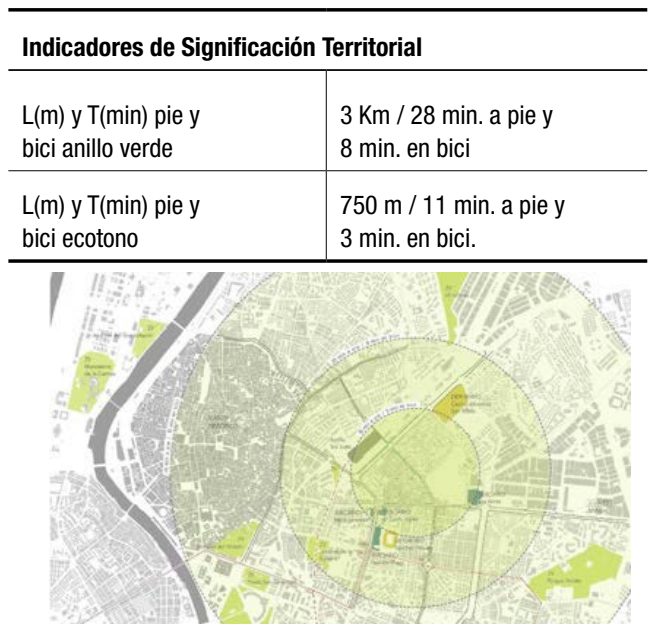

Fig. 12. (Esquema del estudio en la Av. El Greco) 


\section{2.- AFECTACIÓN EN EL TEJIDO URBANO Y SOCIAL DE LAS ÁREAS VINCULADAS. ESCALA BARRIO-CIUDAD:}

Complejidad urbana, mixtura de usos y atractor social. Nivel de afectación en el tejido urbano y social adyacente. Identidades. Fomento del deporte, de la cultura, generador de comunidades, libre uso del espacio público por los niños...). Cercanía a equipamientos sociales, culturales, sanitarios y parques próximos. Potencial de equipamientos

\section{3.- PAISAJE URBANO/CALIDAD ESPACIAL/ DENSIDADES:}

Escala humana. Imagen- contrastes publicidad - elementos urbanos discordantes. / Densidad, Material (volumen edificado), Espacio-visual (disposición y uso), Social. Tamaños, Fragmentación, Continuidades, Formatos, Materialidad. Texturas, color, innovación, ergonomía, permeabilidad, adecuación al contexto y a las temperaturas, etc. Tipo de Edificación, compacidad y densidad. Efecto entorno (barrio, vivienda). Ej. Av. El Greco:

\begin{tabular}{l|l|l}
\hline $\begin{array}{l}\text { Sección de calle, esca- } \\
\text { la y proporciones: Tipo } \\
\text { de Edificación, com- }\end{array}$ & $h=16,17 \mathrm{~m} ; \mathrm{d}=$ & $\begin{array}{l}\text { Relación } \\
\mathrm{h} / \mathrm{d} 0,5-1:\end{array}$ \\
$\begin{array}{l}\text { pacidad y densidad. } \\
\text { (Escala humana) }\end{array}$ & $\mathrm{h} / \mathrm{d}=0,74$ \\
$\mathrm{~h}=16,17 ; \mathrm{d}$ (media \\
calle)=25m \\
\end{tabular}

\section{INDICADORES PAVIMENTOS}

\begin{tabular}{|c|c|c|c|}
\hline $\begin{array}{l}\text { Continuidad Calle corredor ( } 300 \mathrm{~m} \text {.) Acceso y } \\
\text { tránsito: con rutas bien definidas y entradas } \\
\text { y salidas controladas que no comprometan la }\end{array}$ & \multicolumn{3}{|c|}{$\begin{array}{l}\text { Calle corredor: } \\
\text { Actualmente Av. El Greco NO puede considerarse una calle corredor. Ya que, } \\
\text { entre otras causas, no existe continuidad en la accesibilidad peatonal. }\end{array}$} \\
\hline $\begin{array}{l}\text { diseñados para los mismos. Todo el espacio } \\
\text { público debería ser accesible a todos, de forma } \\
\text { que sea posible la vigilancia natural } \\
\text { Promoción del "sentido de propiedad" de los } \\
\text { habitantes respecto a su entorno urbano. }\end{array}$ & \multicolumn{3}{|c|}{$\begin{array}{l}\text { Proximidad a un corredor verde urbano: } \\
\text { Actualmente, desde la calle, tampoco existe acceso a un corredor verde urbano } \\
\text { a una distancia }<600 \mathrm{~m} \text {. La distancia mínima desde Av. El GRECO hasta un espa- } \\
\text { cio verde de significación territorial, como lo es Parque Miraflores, es de } 3 \mathrm{~km} \text {. }\end{array}$} \\
\hline \multirow[t]{6}{*}{ Suelo verde / Suelo no verde } & \multirow[t]{2}{*}{ Suelo verde } & Parterres: $1500 \mathrm{~m}^{2}$ & $1570 \mathrm{~m}^{2}$ \\
\hline & & Alcorques: $1 \mathrm{~m}^{2} \times 70=70 \mathrm{~m}^{2}$ & $6,5 \%$ \\
\hline & \multirow[t]{2}{*}{ Suelo verde } & $\begin{array}{l}\text { Áreas de bioretención+Jardines de lluvia+ } \\
\text { Pavimento sembrado }=3983,06 \mathrm{~m}^{2}\end{array}$ & \multirow[t]{2}{*}{$\begin{array}{c}\mathrm{m}^{2} \\
39 \%\end{array}$} \\
\hline & & Pav. Junta abierta (norte y carril bici): $5660 \mathrm{~m}^{2}$ & \\
\hline & \multirow[t]{2}{*}{ Suelo no verde } & Asfalto: $16773,6 \mathrm{~m}^{2}$ & \multirow{2}{*}{$\begin{array}{c}35700 \\
95,03 \%\end{array}$} \\
\hline & & Acerado: $13265,75 \mathrm{~m}^{2}$ & \\
\hline & \multirow[t]{3}{*}{ Suelo no verde } & Hormigón lavado (plataformas): $2489 \mathrm{~m}^{2}$ & \multirow{3}{*}{$\begin{array}{c}19094 \\
61 \%\end{array}$} \\
\hline & & Hormigón lavado (viario): $7000 m^{2}$ & \\
\hline & & Adoquín cerámico acerado: 9605 & \\
\hline
\end{tabular}




\section{4.- CALIDAD AMBIENTAL:}

Desarrollo de la Red de corredores verdes y espacios libres.

Arbolado y vegetación (Superficie/habitante)Sombra-Alturas-Olores. Espacios de sombra y envolventes. Presencia de agua, abastecimiento, fuentes, riego/drenaje/reciclaje agua (con incorporación de SUDs, Sistemas urbanos de drenaje sostenible), infraestructuras/servicios urbanos. Suelo: Estado y tipo de pavimento (duro, blando, mixto, drenante,..), topografía, poda/limpieza,...

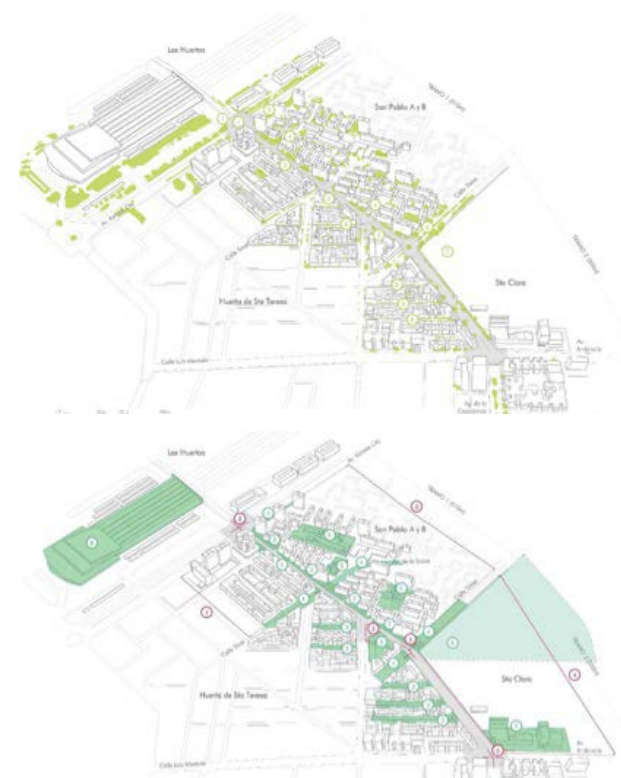

Fig. 13 y 14 (Esquemas del estudio en la Av. El Greco)

Ej. Av. El Greco:

En todo el eje de Av. El Greco la presencia del agua es inexistente.

La actuación incorporará el agua como elemento de mejora de calidad de la calle; con efectos positivos tanto ambientales, como paisajísticos y psicológicos para los ciudadanos.

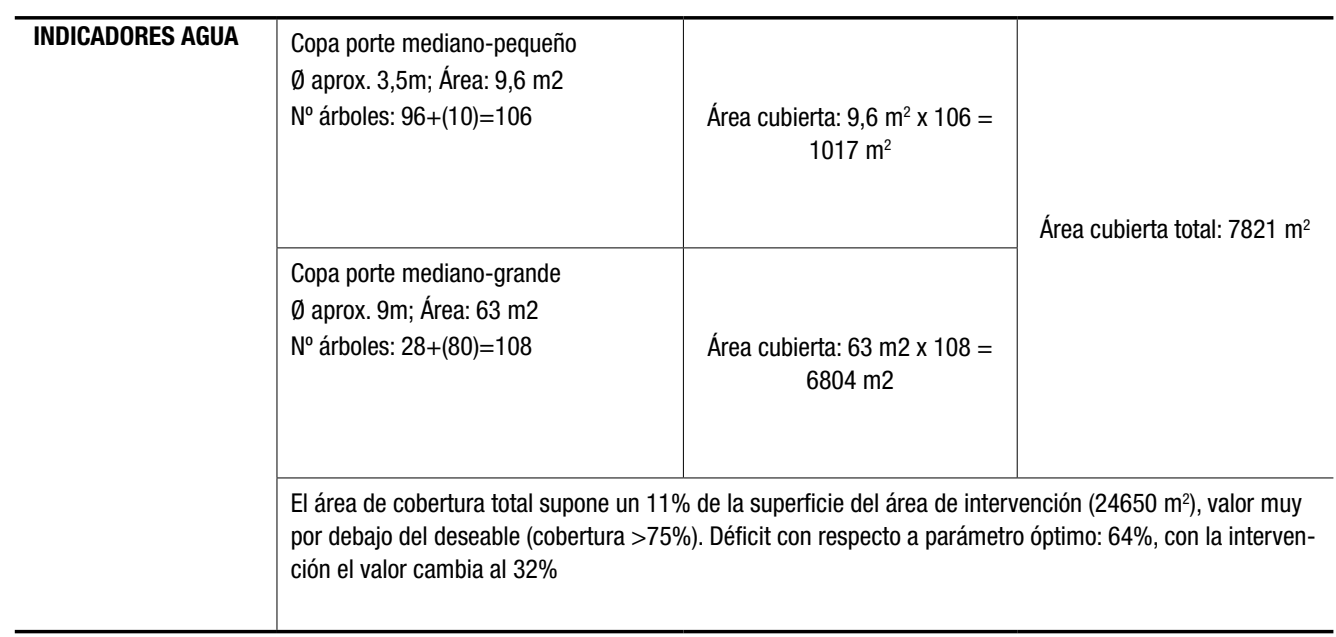




\section{INDICADORES SOMBRA}

$\%$ sombra, cobertura

Cálculo de la sombra / Cobertura. Aproximación de cálculo a partir del tamaño de copa:

\begin{tabular}{|c|c|c|}
\hline $\begin{array}{l}\text { Copa porte mediano-pequeño } \\
\emptyset \text { aprox. } 3,5 \mathrm{~m} \text {; Área: } 9,6 \mathrm{~m}^{2} \\
\mathrm{~N}^{0} \text { árboles: } 96\end{array}$ & $\begin{array}{c}\text { Área cubierta: } 9,6 \mathrm{~m} 2 \times 96 \\
=921 \mathrm{~m}^{2}\end{array}$ & Áron cubiouto totol $2605 \mathrm{~m}^{2}$ \\
\hline $\begin{array}{l}\text { Copa porte mediano-grande } \\
\emptyset \text { aprox. } 9 \mathrm{~m} \text {; Área: } 63 \mathrm{~m}^{2} \\
\mathrm{~N}^{0} \text { árboles: } 28\end{array}$ & $\begin{array}{c}\text { Área cubierta: } 63 \mathrm{~m} 2 \times 28= \\
1764 \mathrm{~m}^{2}\end{array}$ & 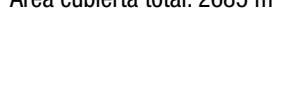 \\
\hline
\end{tabular}

\section{5.- ACCESIBILIDAD/MOVILIDAD:}

Prioridad peatonal y ciclista.

1. Áreas restringidas al tráfico y prioridad al peatón y movilidad reducida ( $75 \%$ viario destinado al peatón, sección acerados, rebajes, plataformas a nivel, rampas, barandillas, anchos, eliminación de obstáculos: comercios ambulantes, vallas, escalones, veladores, pavimento en mal estado o resbaladizo, etc.); 2. Transporte público (densidad de pasajeros), 3. Bici 4. Coche (intensidad del tráfico rodado, disponibilidad de aparcamientos -prever movilidad disfuncional-). Desplazamientos contaminantes: $20-25 \%$.

\section{6.- RECURSOS DISPONIBLES:}

Ajuste económico equilibrado, generador de economía y empleo. Actividades ciudadanas vinculadas al buen uso y mantenimiento del espacio: rutas, deportes, huertos... Atractivo turístico. Grado de productividad o autoconsumo (Huertos).

Gestión, Mantenimiento, Reciclaje urbano y autonomía. Reducción de costes: Capacidad de reciclaje de elementos disponibles y tratamiento de aguas. Existencia de pendientes, red separativa, elementos patrimoniales, sistemas de recogida de residuos, reutilización de aguas pluviales para riego, huertos, etc. Minimización del mantenimiento, sistemas de recogida de residuos.

\section{7.- SEGURIDAD:}

Inmunidad/Seguridad/Inclusión Social/ Iluminación.

Diseño urbano seguro: base principio de "ver y ser visto". Continuidad $300 \mathrm{~m}$. Callecorredor. Acceso y tránsito: con rutas bien definidas y entradas y salidas controladas que no comprometan la seguridad. Estructura clara de usos con lugares diseñados para los mismos. Todo el espacio público debería ser accesible a todos, de forma que sea posible la vigilancia natural. Promoción del "sentido de propiedad" de los habitantes respecto a su entorno urbano. Protección física con un diseño adecuado para las funciones de seguridad. Itinerarios y lugares de juego seguros. También resulta imprescindible para la seguridad la existencia de actividad en el espacio público y una gestión del mantenimiento adecuada con participación de los vecinos.

\section{8.- VIDA URBANA:}

Actividades/Usos.

Actividad del tejido social existente (Asociaciones vecinales, etc.). Actividades ciudadanas existentes vinculadas al buen uso y mantenimiento del espacio: rutas, deportes, huertos, etc. Espacios intergeneracionales, Niveles de ocupación del lugar. Temporalización del espacio público, vigilancia natural. Actividades de 
proximidad: apoyo pequeño comercio local... Vinculación de las actividades de los locales comerciales o equipamientos al espacio: mercadillo, exposiciones, etc.

\section{9.- MOBILIARIO URBANO:}

Bancos, juegos, elementos de sombra, servicios públicos, fuentes, paradas bici y bus, cabinas, contenedores, elementos de accesibilidad (braille, barandillas, etc.), zona de estacionamiento especial, intercambiadores, etc. TIC, eficiencia energética y lumínica. Ergonomía y habitabilidad térmica.

\section{0.- GESTIÓN Y PARTICIPACIÓN CIUDADANAS/MANTENIMIENTO Y AUTONOMÍA:}

Favorecer a colectivos: niños, mayores y mujeres. El indicador sobre la participación de los vecinos va a resultar imprescindible para la seguridad, la existencia de actividad en el espacio público y una gestión o mantenimiento adecuada del espacio urbano.

>> De los aspectos a tener en cuenta en el proceso de las obras de la Avenida El Greco, han sido las reuniones periódicas con los ve-

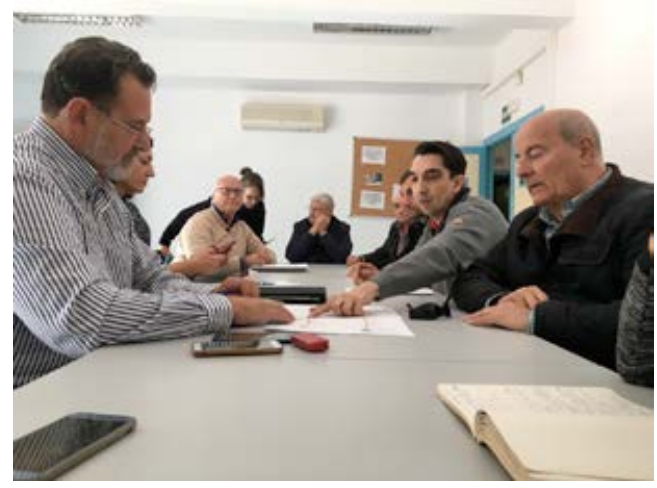

Fig. 15. Proceso informativo-colaborativo durante las obras de la Av. El Greco cinos y fundamentalmente comercios locales afectados directamente, a los que se le ha ido informando de los avances de las obras semanalmente, y con los que se han acordado cuestiones de diseño del proyecto (como por ejemplo la ubicación de contenedores y zonas de carga y descarga, algunas modificadas para beneficio de sus usuarios), así como el faseado de las obras por tramos para perjudicar lo mínimo posible a los comercios (del mismo modo que se ha procedido en otros procesos participativos como el de la Calle Baños ${ }^{8}$ ). También se ha diseñado con ellos la señalización e itinerarios de las obras para facilitar el acceso a los portales de viviendas y comercios.

>> Mediante la Acción "Mercado Abierto El Greco", llevada a cabo con los comerciantes de la Avenida durante las obras, se impulsó un concepto similar al "Zoco" a lo largo de toda la Avenida durante las Navidades 2018-2019 con el propósito, por una parte, de apoyar el Comercio local (y evitar las bolsas de plástico regalando bosas de tela a todos los comercios y vecinos) y por otra, equilibrar mediante esta campaña las posibles pérdidas que pudieran tener por las molestias de las obras. Parte de la

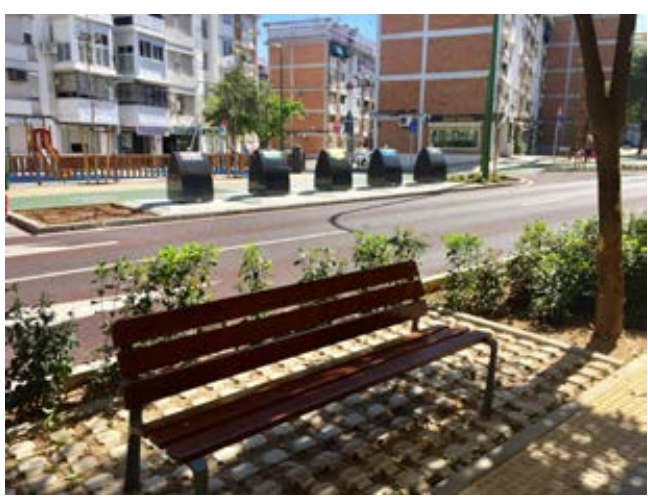

Fig. 16. Fotografías del estado actual de la Av. El Greco

8 http://planreaviva.org/calle-banos/ 
campaña "Yo compro en mi barrio" fue el Video donde además se reconocen los propios comerciantes y vecinos como espacio de proximidad y confianza ${ }^{9}$.

Ha sido especialmente importante eliminación de la superficie de calzada antes sobredimensionada, y la inclusión (como ejemplo piloto en la Ciudad de Sevilla) de los SISTEMAS SUDS para el drenaje, captación de aguas y riego; así como la plantación de una enorme variedad de especies arbustivas

“(...) la calle siempre se mantiene el carácter de zona verde que se consigue con la alternancia de parterres y con la disposición al mismo nivel de un pavimento mixto de piezas con juntas abiertas, con subbase drenante e intersticios ajardinados que permiten la absorción del agua en el terreno. El verde se mezcla con las zonas de estancia y recreo para configurar un espacio con mucha potencialidad, con un ajardinado diverso y sostenible, eligiendo cuidadosamente las especies entre arbustivas vivaces para contribuir a enriquecer la biodiversidad y el subsuelo, teniendo en cuenta la adecuación al entorno, el mantenimiento, los colores de las hojas, de la floración, las texturas y las alturas de las plantas para conseguir el querido efecto envolvente. En medio de esta faja verde la remodelación conserva los árboles existentes, y se crean unas nuevas líneas de arbolado de diferente tipología y altura.

9 VIDEO “MERCADO ABIERTO EL GRECO” https://www. youtube.com/watch?v=hkOx7xuSayE
También se ha incrementado la diversidad de especies vegetales que, junto con los jardines de lluvia para la recogida y almacenamiento de las precipitaciones, pavimentos permeables, una nueva red de riego por goteo y zonas ajardinadas accesibles, aumentan en un 50 por ciento el suelo verde, que incluye áreas de biorretención.

Una jardinería estudiada y bien ejecutada donde destaca el rosal floricundio Jardins de France de Rosales Ferrer, junto con floraciones de Gaura lindheimeri, Lantanas cámara, Thymus vulgaris, Santolina chamaeciparyssus, Clorophytum elatum variegatum, Acanthus mollis,Dipladenias etc. (...)"

José Elías Bonet, Octubre 2019, Jardines sin fronteras

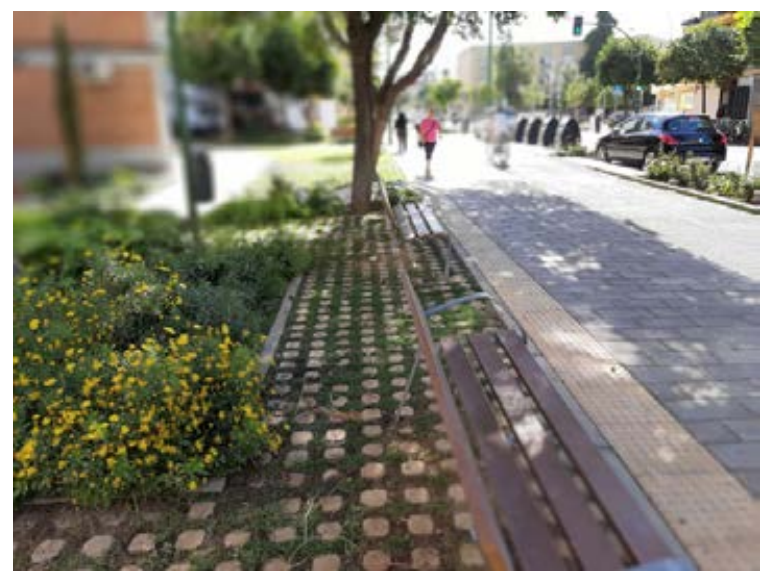

Fig. 17. Avda.El Greco. Pavimento drenante.

No estamos del todo seguros de si este es un cambio de paradigma suficiente -en cuanto al urbanismo se refiere- para frenar las graves $y$ 
devastadoras consecuencias ambientales que estamos sufriendo en nuestro planeta y en nuestras vidas; pero seguro supone un avance en la búsqueda de soluciones.

\section{ANEXO 1:}

\section{VALORACIÓN CUANTITATIVA: INCIDENCIA A CORTO Y MEDIO PLAZO}

\section{SIGNIFICACIÓN TERRITORIAL}

\begin{tabular}{l|l}
\hline \multicolumn{1}{l}{ 1.- Significación territorial } \\
\hline Cercanía a un intercambiador o sistema general. & Minutos a pie y en bici \\
\hline $\begin{array}{l}\text { Cercanía a un centro urbano o área comercial de } \\
\text { impacto metropolitano }\end{array}$ & Minutos a pie y en bici \\
\hline
\end{tabular}

2. AFECTACIÓN EN EL TEJIDO URBANO Y SOCLAL DE LAS ÁREAS VINCULADAS

\begin{tabular}{l|l}
\hline \multicolumn{2}{l}{ 2.- Afectación en el tejido urbano y social. Escala barrio-ciudad } \\
\hline Densidad poblacional adyacente & Habitantes/Superficie \\
\hline Elementos de atracción social, cultural, turístico & $\mathrm{N}^{0}$ de equipamientos sociales, culturales, sanitarios y parques próximos \\
\hline
\end{tabular}

\section{PAIS AJE URBANO / CALIDAD ESPACLAL / DENSIDADES}

\section{3.- Paisaje urbano/Calidad espacial/Densidades:}

\begin{tabular}{|c|c|}
\hline $\begin{array}{l}\text { Sección de calle, escala y propor- } \\
\text { ciones: } \\
\text { Tipo de Edificación, compacidad y } \\
\text { densidad. (Escala humana) }\end{array}$ & $\begin{array}{l}\text { (de BCNecologia_Gobierno) } \\
\text { PROPORCIÓN DE CALLE } \\
\text { La proporción de calle (h/d) permite determinar el grado de percepción de la compacidad } \\
\text { de un tejido urbano a escala del peatón. La referencia es la proporción que existe entre la } \\
\text { distancia entre dos fachas y la altura de los edificios de los que forman parte. Esta varia- } \\
\text { ble h/d (metros altura / metros anchura) incide en el confort térmico y lumínico de la calle, } \\
\text { así como también en la percepción de equilibrio que se da entre el volumen edificado y el } \\
\text { porcentaje de cielo que se visualiza desde el espacio público. Informa de la presión que } \\
\text { ejerce la compacidad de un tejido urbano en la sección de calle. } \\
\text { La clasificación de los tramos de calle en función del grado de apertura de vista en el } \\
\text { cielo se desglosa en: } \\
\text { - Relación h/d excelente < } 0,5 \\
\text { - Relación h/d buena 0,5-1 (de CONFORT: Valor óptimo: h/d<1 } 50 \% \text { de los tramos) } \\
\text { - Relación h/d suficiente } 1-2 \\
\text { - Relación h/d insuficiente 2-3,5 (de CONF0RT: Valor mínimo: h/d<2 } 50 \% \text { de los tramos) } \\
\text { - Relación h/d muy insuficiente }>3,5 \\
\text { PRca (\%)= [tramos de calle (metros lineales) con una relación h/d suficiente, buena o ex- } \\
\text { celente / tramos del viario público total (metros lineales)] }\end{array}$ \\
\hline Contaminación visual & $\begin{array}{l}N^{0} \text { de elementos urbanos discordantes: publicidad, contrastes, obstáculos (comercios } \\
\text { ambulantes, vallas, escalones, veladores, pavimento en mal estado o resbaladizo), discon- } \\
\text { tinuidades, etc. }\end{array}$ \\
\hline Materialidad & Diversidad de texturas y color \\
\hline Topografía y perspectivas & Pendientes (\%) y cambios de dirección de la vía \\
\hline
\end{tabular}


4. CALIDAD AMBIENTAL

\section{4.- Calidad ambiental:}

Viario público para el transporte $(25 \%)$

(de PEISAU2008SE y CONFORT)

- REPARTO ÓPTIMO DEL VIARIO PÚBLICO:

Viario público destinado al peatón y otros usos del espacio público (vehículos de residentes, carga y descarga, vehículos de emergencias, servicio de taxi), superior al $75 \%$.

Viario público destinado al tránsito de vehículos privados de paso y transporte público de superficie, inferior al $25 \%$

Superficie viario público peatonal $\left(\mathrm{m}^{2}\right) /$ superficie viario público total $\left(\mathrm{m}^{2}\right) * 100$

Viario público para el peatón $(75 \%)$

Áreas restringidas al tráfico: longitud y el porcentaje de áreas preferentes para peatones ¿y bicicletas?

Continuidad Calle corredor $(300 \mathrm{~m}$.)

Acceso y tránsito: con rutas bien definidas y entradas y salidas controladas que no comprometan la seguridad

Estructura clara de usos con lugares diseñados para los mismos

Todo el espacio público debería ser accesible a todos, de forma que sea posible la vigilancia natural

Promoción del "sentido de propiedad" de los habitantes respecto a su entorno urbano (de PEISAU2008SE)

- CONTINUIDAD ESPACIAL Y FUNCIONAL DE LA CALLE CORREDOR. GRADO DE INTERACCIÓN DE LAS SECUENCIAS ESPACIALES

TRAMOS DE CALLE (M LINEALES) CON INTERACCIÓN MUY ALTA 0 ALTA SUPERIOR AL 25\%

GRADO DE INTERACCIÓN DE LOS TRAMOS DE CALLE:

1. INTERACCIÓN MUY ALTA. Espacio de tránsito peatonal (viario peatonal_75\%) y densidad de actividades_10/100 m (1 actividad cada 10m recorridos)

2. INTERACCIÓN ALTA. Espacio de tránsito peatonal y/o vehicular (viario peatonal_25\% y $<75 \%$ ) y densidad de actividades_5/100 m (1 actividad cada

20m recorridos)

3. INTERACCIÓN MEDIA. Espacio de tránsito peatonal y/o vehicular (viario peatonal_25\% y $<75 \%$ ) y densidad de actividades_5/100 m (1 actividad cada

$20 \mathrm{~m}$ recorridos) 0 espacio de tránsito peatonal (viario peatonal _75) y densidad de actividades 5-10/100 m

4. INTERACCIÓN BAJA. Espacio de tránsito vehicular (viario peatonal $<25 \%$ ) 0 espacio de tránsito peatonal (viario peatonal_75) y densidad de actividades_5/100 m

5. INTERACCIÓN MUY BAJA. Espacio de tránsito vehicular (viario peatonal $<25 \%$ ) y densidad de actividades $<2 / 100 \mathrm{~m}$ (1 actividad cada 50m recorridos) o espacio sin actividades

- ACCESIBILIDAD DEL CORREDOR VERDE: ANCHURA MÍN. DE 2,5 M. Y PENDIENTE INFERIOR AL 6\%

- PROXIMIDAD A CORREDORES VERDES URBANOS

ACCESO A UN CORREDOR VERDE URBANO A UNA DISTANCIA INFERIOR DE 600 METROS DESDE CUALQUIER PUNTO DE LA CIUDAD.

Fórmula de cálculo: Tramos de calle con acceso a corredor verde urbano (m. lineales) / metros lineales totales * 100

Definición de corredores verdes urbanos.

Establecer una continuidad del verde urbano, logrando la integración de los distintos componentes de la vegetación de la ciudad. Existencia de una red de corredores verdes en el interior del tejido urbano

(de PEISAU2008SE)

NoÁrbol/Superficie edificada:

Dotación óptima de arbolado: 1 árbol por cada $20 \mathrm{~m}^{2}$ de superficie edificada

CALLE RED BÁSICA: MÍNIMO 200 ÁRBOLES/KM DE CALLE, EN DOBLE ALINEACIÓN.

CALLE RED SECUNDARIA: MÍNIMO 400 ÁRBOLES/KM DE CALLE, EN DOBLE ALINEACIÓN 0 MÁS

Arbolado y vegetación

VALOR MÍNIMO DE 10M² (TENDENCIA DE 20M²) DE VERDE URBANO POR HABITANTE. 
Densidad de árboles por tramo de calle
(VG).

- DENSIDAD DE ÁRBOLES POR TRAMO DE CALLE

Relación entre el número de árboles y los metros lineales totales de cada tramo de calle de la ciudad. Si el arbolado es de porte pequeño la densidad máxima es de 0,50 árboles/metro y si el arbolado es de gran porte la densidad máxima es de 0,2 árboles/metro, en alineación doble. Se considera un valor adecuado de densidad de arbolado cuando el $50 \%$ de la longitud potencial (tramos con $>8 \mathrm{~m}$ de ancho) tienen un valor de densidad igual 0 superior a 0,2 árboles $/ \mathrm{m}$.

Deseable: Criterio $>0,2^{\star}$ árboles/ $\mathrm{m}$ Cobertura $>75 \%$ de los tramos de calle ${ }^{\star} E$ El valor deseable del indicador dependerá de las características específicas de la calle (anchura, profundidad de pavimento, etc.) y del porte de los árboles plantados

$(\mathrm{VG})$.

\section{- DIVERSIDAD DEL ARBOLADO URBANO}

Evaluar la diversidad de especies que componen el arbolado de la ciudad. Los árboles presentes en las calles, parques y jardines de la ciudad son un elemento estructural del hábitat urbano. Mantener una elevada diversidad de árboles potencia la biodiversidad de otras especies en el ecosistema urbano

(VG).

\section{- PERCEPCIÓN ESPACIAL DEL VERDE URBANO}

Proporción del volumen verde de un tramo de calle respecto al campo visual del peatón.

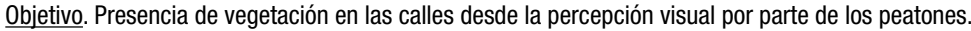

Definición del indicador. Fracción de espacio del campo visual que ocupa la vegetación en la calle. Esta fracción se calcula a partir del volumen que representan los árboles, arbustos y parterres en función de su tipología y porte. La unidad en la que se expresa es en porcentaje de volumen verde por tramo de calle.

A partir del conocimiento de la especie de árbol, es posible la clasificación en categorías de arbolado en gran porte, mediano y pequeño. A cada una de estas categorías de arbolado le corresponde un volumen verde asociado en función de su tamaño. Campo visual $=[$ longitud del tramo $\mathrm{x}$ ancho de calle $\times 8$ de altura)] Volumen de las copas $=[4 / 3 \times \sqcap \times$ r3]

Percepción excelente: Volumen verde $>30 \%$ del campo visual Percepción buena: Volumen verde entre $20 \%$ y $30 \%$ del campo visual Percepción suficiente: Volumen verde entre $10 \%$ y $20 \%$ del campo visual Percepción insuficiente: Volumen verde entre $5 \%$ y 10\% del campo visual Percepción muy insuficiente: Volumen verde $<5 \%$ del campo visual

PEverde $(\%)=$ [superficie de viario público con volumen verde superior al $10 \% /$ superficie de viario público total] $\times 100$

\section{(De BCNecologia_ Gobierno)}

\section{- PERCEPCIÓN ESPACIAL DEL VERDE URBANO}

Porcentaje del campo visual que, en el espacio público, está ocupado por la vegetación. El análisis tiene en cuenta, sobre todo, el arbolado como el elemento vegetal característico del viario urbano a partir de sus características formales. El arbolado se clasifica el arbolado en tres tipologías de porte: pequeño, mediano y grande. Los árboles de porte pequeño representan aquellas especies cuya copa no excede los 4 metros de anchura, las de porte medio tienen entre 4 y 6 metros de ancho y las de gran porte son todas aquellas que superan los 6 metros de copa.

Más allá de un criterio estético, la presencia de arbolado contribuye a la mejora del confort climático del espacio público, actuando como elemento atenuante de las condiciones extremas de temperatura a nivel de calle.

El volumen verde está condicionado, además, por el ancho de las calles, ya que este determina el área del campo visual del peatón. Puede darse el caso de que calles estrechas, con especies de porte pequeño, tengan más \% de volumen verde que otras calles más anchas con árboles de porte mayor. Se considera que el $10 \%$ es una proporción mínima de volumen verde. Menos del 10\% equivale a calles con una baja presencia visual del verde y prácticamente nula cuando se encuentra por debajo del $5 \%$.

PEverde $(\%)=[$ superficie de viario público con un volumen verde superior al $10 \%$ / superficie de viario público total]

La presencia de verde es fundamental en la variable psicológica. Esta presencia no sólo queda restringida a los espacios verdes 0 ajardinados sino que se extiende al conjunto de espacios públicos. El campo visual de una calle desde un punto central de éste está conformado por verde urbano, como mínimo, en un $30 \%$. 


\begin{tabular}{|c|c|}
\hline $\begin{array}{l}\text { Mantenimiento suelos, } \\
\text { poda, limpieza, etc }\end{array}$ & Servicios públicos \\
\hline Habitabilidad térmica & $\begin{array}{l}\text { (de PEISAU2008SE) } \\
\text { - CONFORT TÉRMICO. OBSTRUCCIÓN DE RADIACIÓN SOLAR DEL ARBOLADO EN EL VIARIO PÚBLICO } \\
\text { Fórmula de cálculo: Superficie obstruida (sombras arrojadas por el arbolado) ( } \mathrm{m}^{2} \text { ) / superficie total viario } \\
\text { público }\left(\mathrm{m}^{2}\right)^{*} \text { * } 100 \\
\text { (VG). } \\
\text { - CONFORT TÉRMICO } \\
\text { Objetivo. Potencial de confort térmico de la trama urbana en términos de horas útiles a lo largo del día con } \\
\text { niveles adecuados de confort para un peatón. } \\
\text { Definición del indicador. Porcentaje de horas entre las } 8 \text { hrs y las } 22 \text { hrs en las cuales una calle ofrece las } \\
\text { condiciones adecuadas de confort térmico para una persona. El confort térmico tiene en consideración } \\
\text { cuatro aspectos importantes: el clima, la morfología de la calle, los materiales en pavimentos y fachadas, } \\
\text { la presencia de vegetación y actividad metabólica del individuo. La unidad del indicador se expresa en \% } \\
\text { de las } 15 \text { horas útiles al día. } \\
\text { Caracterizar los tramos de calle por tipología de sección, lo cual significa clasificarlos según orientación, } \\
\text { proporción entre altura y distancia entre fachadas ( } h / d \text { ) y presencia de vegetación. } \\
\text { Potencial de confort en verano excelente: }>80 \%=>12 \text { horas al día. Potencial de confort en verano bueno: } \\
66 \% \text { a } 80 \%=9 \text { a } 12 \text { horas al día. Potencial de confort en verano suficiente: } 50 \% \text { a } 66 \%=7,5 \text { a } 9 \text { horas } \\
\text { al día. Potencial de confort en verano insuficiente: } 35 \% \text { a } 50 \%=5 \text { a } 7,5 \text { horas al día. Potencial de confort } \\
\text { en verano muy insuficiente: < } 35 \%=<5 \text { horas al día } \\
\text { Cter (\%)= [superficie de viario público con potencial de confort en verano superior al } 50 \% \text { / superficie de } \\
\text { viario público total] x } 100 \\
\text { (De CONFORT) } \\
\text { - CONFORT TÉRMICO } \\
\text { Obstrucción mínima del } 30 \% \text { de radiación solar en el espacio público (sombras arrojadas por el arbo- } \\
\text { lado). Potencial mínimo de } 50 \% \text { de horas útiles de confort al día } \\
\text { Superficie obstruida (sombras arrojadas por el arbolado )( } \mathrm{m}^{2} \text { ) / superficie total viario público ( } \mathrm{m}^{2} \text { ) * } 100\end{array}$ \\
\hline
\end{tabular}




\begin{tabular}{|c|c|c|c|c|}
\hline Habitabilidad acústica & $\begin{array}{l}\text { (de PEISAU2 } \\
-\quad \text { CONFOR } \\
\text { PORCENTAJ } \\
\text { NIVEL SONO } \\
\text { Nivel } \\
<65 \mathrm{dBA} \\
65-70 \mathrm{dBA} \\
>70 \mathrm{dBA} \\
\text { ASFALTO S0 } \\
\text { Fórmula de } \\
\text { 10·log (FL + }\end{array}$ & $\begin{array}{l}\text { E) } \\
\text { ÚSTICO } \\
\text { POBLACIÓN EXPU } \\
\text { IURNO NIVEL SO } \\
\text { Cobertura } \\
60 \% \text { población } \\
\text { 15\% población } \\
25 \% \text { población } \\
\text { EUCTOR EN VÍAS } \\
\text { lo: Población expu } \\
\text { P) - 10·log (X) (en } \\
\text { lación expuesta } \\
\text { to: <65 dBA (60\% } \\
\text { urno: <55 dBA (6C } \\
\text { ta según nivel eq } \\
55+10 \cdot \log \text { (FL } \\
\text { RNo }\end{array}$ & $\begin{array}{l}\text { A A NIVELES } \\
\text { R0 NOCTURI } \\
\text { Nivel } \\
<55 \mathrm{dBA} \\
55-60 \mathrm{dBA} \\
>60 \mathrm{dBA} \\
\text { SICAS } \\
\text { a según nivel } \\
\text { A) } \\
\text { in nivel de ru } \\
\text { blación); } 65- \\
\text { Joblación); } 5 \\
\text { lente sonoro } \\
\text { ·FP) - 10·log }\end{array}$ & $\begin{array}{l}\text { NOROS: } \\
\text { Cobertura } \\
60 \% \text { población } \\
15 \% \text { población } \\
25 \% \text { población } \\
\text { uivalente sonoro / población total * } 100 \text { Leq = } 55+ \\
\text { dBA ( } 15 \% \text { población); > } 70 \text { dBA ( } 25 \% \text { población). } \\
0 \text { dBA ( } 15 \% \text { población); > } 60 \text { dBA ( } 25 \% \text { población). } \\
\text { oblación } \\
\text { (en dBA) }\end{array}$ \\
\hline $\begin{array}{l}\text { Índice de habitabilidad } \\
\text { en el espacio público }\end{array}$ & $\begin{array}{l}\text { (VG). } \\
\text { Variables erc } \\
\text { Espacio } \\
\text { Accesibi } \\
2.5 \mathrm{~m} \text { y } \\
5 \% 8 \% \text {, } \\
\text { Proporci } \\
\text { Variables psi } \\
\text { PRESEN } \\
\text { Percepci } \\
\text { Densida } \\
\text { Diversid } \\
\text { Variable } \\
\text { Confort } \\
\text { Confort } \\
\text { Calidad }\end{array}$ & $\begin{array}{l}\text { nicas (15 puntos } \\
\text { nado al peatón (\% } \\
\text { (personas con m } \\
\text { entes < } 5 \%,(3) \\
\text { ceras < } 0.9 \mathrm{~m} \text { y/0 } \\
\text { la calle (relación } \\
\text { gicas ( } 15 \text { puntos } \\
\text { E AGUA } \\
\text { el verde (\% camp } \\
\text { actividades atract } \\
\text { bana (bits de info } \\
\text { lógicas (15 punto } \\
\text { co (\% hrs útiles a } \\
\text { ico ( } \mathrm{dB} \text { A diurno) } \\
\text { ire (N0x g/m3) }\end{array}$ & $\begin{array}{l}\text { imo) } \\
\text { lle): (5) >75\% } \\
\text { dad reducida } \\
\text { era }>0.9 \mathrm{~m} \\
\text { idientes > } \\
\text { ): (5) }<0,5 \text {, } \\
\text { imo) } \\
\text { sual) } \\
\text { (cada } 100 \mathrm{~m} \\
\text { ividuo) } \\
\text { láximo) } \\
\text { ) }\end{array}$ & 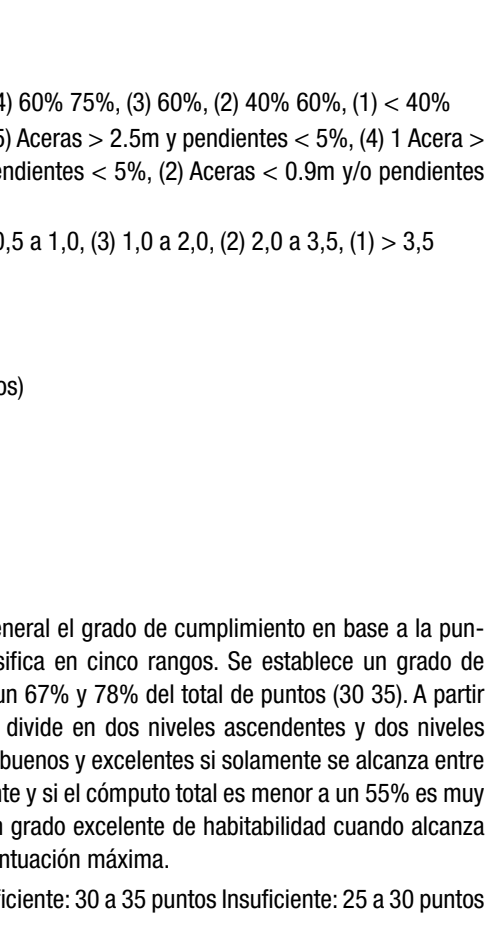 \\
\hline
\end{tabular}




\section{ACCESIBILIDAD / MOVILIDAD}

\section{5.- Accesibilidad/Movilidad:}

Áreas restringidas al tráfico y prioridad al peatón y mov. reducida $(75 \%$ viario destinado al peatón, sección acerados, rebajes, plataformas a nivel, rampas, barandillas, anchos, eliminación de obstáculos: comercios ambulantes, vallas, escalones, veladores, pavimento en mal estado o resbaladizo, etc.)
(De BCNecologia_Gobierno)
- $\quad$ ACCESIBILIDAD DEL VIARIO

El indicador pondera la accesibilidad de los tramos de calle en función del ancho de las aceras y de la pendiente del trazado, asumiendo que ambos atributos pueden limitar los desplazamientos de personas con movilidad reducida.

Una vez obtenidos los datos de anchura y pendiente, éstos se organizan a partir de los requerimientos mínimos de accesibilidad de una persona en silla de ruedas. Como criterio general, las aceras se consideran accesibles a partir de $90 \mathrm{~cm}$ de ancho y las pendientes como máximo hasta un $5 \%$.

En función de las dimensiones de las aceras y de la pendiente de los tramos, se establecen las siguientes categorías:

- Accesibilidad excelente (pendiente $<5 \%$ y aceras de más de $2,5 \mathrm{~m}$ de anchura)

- Accesibilidad buena (pendiente $<5 \%$ y una acera de más de 2,5 metros de ancho)

- Accesibilidad suficiente (pendiente $<5 \%$ y una acera de más de 0,9 metros de ancho)

- Accesibilidad insuficiente (pendiente entre 5 y $8 \%$ y/0 aceras de menos de 0,9 metros)

- Accesibilidad muy insuficiente (pendiente $>8 \%$ y/0 aceras de menos de 0,9 metros) Indicador complementario. Para cada sección de tramo de calle, porcentaje de espacio destinado al peatón. Valor mínimo: $>60 \%$

Aviario $(\%)=$ [tramos de calle (metros lineales) con accesibilidad suficiente, buena 0 excelente / tramos del viario total (metros lineales)]

Accesibilidad a la movilidad reducida. Accesibilidad (rampas, barandillas, )

(VG).

Accesibilidad excelente Pendiente $<5 \%$ y aceras de más de $2,5 \mathrm{~m}$. de ancho.

Accesibilidad buena Pendiente $<5 \%$ y una acera de más de 2,5 metros de ancho.

Accesibilidad suficiente Pendiente $<5 \%$ y una acera de más de 0,9 metros de ancho.

Accesibilidad insuficiente Pendiente entre 5 y $8 \%$ y/0 aceras de menos de 0,9 metros.

Accesibilidad muy insuficiente Pendiente $>8 \%$ y/0 aceras de menos de 0,9 metros

Transporte público (densidad de pasajeros)

Paradas transporte público (de PEISAU2008SE)

- ACCESO A PARADA/AS DE TRANSPORTE PÚBLICO A UNA DISTANCIA INFERIOR DE 300 METROS DESDE CUALQUIER PUNTO DE LA CIUDAD.

Fórmula de cálculo: Tramos de calle con cobertura de transporte público (m. lineales) / metros lineales totales * 100

Proximidad a paradas de transporte público de superficie (distancia inferior de 300 metros)

Red y plazas de aparcamiento de bicicletas (distancia inferior de 300 metros)

dotación de plazas de aparcamiento (distancia inferior de 300 metros)

(de PEISAU2008SE)

- Acceso a aparcamiento de bicicletas a una distancia inferior de 300 metros 


\section{RECURSOS DISPONIBLES}

\section{6.- Recursos disponibles:}

\begin{tabular}{|c|c|}
\hline Economía y empleo & $\begin{array}{l}\text { Atractivo turístico. Generador de empleo. } \\
\text { Grado de productividad o autoconsumo (Huertos). } \\
\text { Reciclaje, Gestión, Mantenimiento y autonomía }\end{array}$ \\
\hline $\begin{array}{l}\text { Metabolismo urbano, servicios e } \\
\text { infraestructuras }\end{array}$ & $\begin{array}{l}\text { (de PEISAU2008SE) } \\
\text { Reserva de espacio para mobiliario urbano de recogida. } \\
\text { Acceso a un punto limpio a una distancia inferior de } 600 \text { metros } \\
\text { Espacios para procesos de autocompostaje comunitario y huertos urbanos en espacios libres y/0 } \\
\text { cubiertas de edificios. Óptimo: Recuperación del } 50 \% \text { de materia orgánica. } \\
\text { Canalización de los flujos residuales en el subsuelo; recogida neumática de residuos } \\
\text { Materiales reutilizables, reciclados y renovables en obras } \\
\text { Minimización y recuperación de los residuos generados en la construcción y demolición } \\
\text { Estado/Durabilidad/mantenimiento de los elementos diseñados (deterioro, vandalismo) } \\
\text { Rendimiento económico (turismo, cultura, etc.) }\end{array}$ \\
\hline Biodiversidad y Ecología glocal & $\begin{array}{l}\text { Acceso de los ciudadanos a espacios verdes } \\
\text { "Lugares que funcionen como válvulas de escape": zona verde de dimensión suficiente para que } \\
\text { una persona pueda considerarse "fuera" de un lugar cementado, y que se encuentre a menos de } \\
300 \text { m de su vivienda. Poder andar, ir en bicicleta o realizar deporte en ambientes más naturales }\end{array}$ \\
\hline CICLO INTEGRAL DEL AGUA & \\
\hline Presencia hídrica & Existencia de fuentes de agua potable y sistema de riego \\
\hline Pavimentos permeables: $\left(\% m^{2}\right)$ & $\begin{array}{l}\text { (de PEISAU2008SE) } \\
\text { - ÍNDICE DE PERMEABILIDAD } \\
\text { Urbanización de bajo impacto. Reducir el sellado y la impermeabilización del suelo } \\
\text { ÍNDICE DE PERMEABILIDAD SUPERIOR AL } 30 \% \text { EN ÁREAS CON UN COEFICIENTE DE } \\
\text { EDIFICABILIDAD GLOBAL MAYOR DE } 0,5 \text { (M²C/ M²S) } \\
\text { Fórmula de cálculo: } \\
\text { ( } \text { área suelo * factor de permeabilidad) / superficie urbana *100 } \\
\text { (de PEISAU2008SE y VG) } \\
\text { - Factor de permeabilidad: } \\
\text { - Superficies permeables: F=1 (espacios verdes sobre suelo natural; se desarrolla flora y fauna) } \\
\text { - Espacios verdes sin conexión con suelo natural. Espacios con vegetación con más de } 80 \mathrm{~cm} \text { de } \\
\text { tierra vegetal fértil. F: } 0,7 \\
\text { - Espacios verdes sin conexión con suelo natural. Espacios con vegetación sobre parkings sub- } \\
\text { terráneos, (ecoparkings) cubiertas verdes intensivas con menos de } 80 \text { cm. de tierra vegetal fértil. } \\
\text { F: } 0,5 \\
\text { - Superficies semipermeables: F=0,5 (pavimentos que permiten el traspaso de aire y agua, e } \\
\text { infiltración: pavimento de piedra, con caja de pavimento de grava/arena) } \\
\text { - Superficies impermeabilizadas parcialmente. Pavimentos que permiten el traspaso de aire y } \\
\text { agua. Normalmente sin plantaciones. Como pavimentos de piedra, con caja de pavimentos de } \\
\text { grava y arena. F: } 0,3 \\
\text { - Superficies impermeables: F=0. (asfalto, los adoquines, edificios, construcciones, etc.) } \\
\text { - Infiltración de aguas pluviales en m2. Infiltración a las capas freáticas, a través de espacios } \\
\text { verdes. F: } 0,2 \\
\text { - Verde vertical (hasta } 10 \text { metros). Paredes y muros cubiertos de vegetación. F: } 0,5 \\
\text { - Cubiertas verdes. Azoteas cubiertas de vegetación que permiten recoger el agua de la lluvia. } \\
\text { Extensivas } 0 \text { intensivas, con más de } 80 \text { cm. de tierra fértil. F: } 0,7\end{array}$ \\
\hline
\end{tabular}




\begin{tabular}{l|l}
\hline Áreas de biorretención & $\mathrm{m}^{3}$ Cunetas verdes, estanques de retención, pozos y zanjas de infiltración \\
\hline $\begin{array}{l}\text { Redes separativas no conven- } \\
\text { cionales de aguas pluviales y de } \\
\text { aguas grises }\end{array}$ & \\
\hline
\end{tabular}

\section{SEGURIDAD}

\begin{tabular}{l|l}
\hline \multicolumn{2}{l}{ 7.- Seguridad: } \\
\hline $\begin{array}{l}\text { Inmunidad / Seguridad / Inclusión Social / } \\
\text { Iluminación }\end{array}$ & $\begin{array}{l}\text { (de AL21SE) } \\
\mathrm{N}^{0} \text { total de delitos/1000 personas * año }\end{array}$ \\
\hline $\begin{array}{l}\text { Acceso y tránsito: Itinerarios y lugares de juego } \\
\text { seguros. Rutas bien definidas y entradas y salidas } \\
\text { controladas que no comprometan la seguridad }\end{array}$ & $\begin{array}{l}\text { Elementos de señalización } \\
\text { Braile } \\
\text { Pavimento antideslizante }\end{array}$ \\
\hline $\begin{array}{l}\text { Estructura clara de usos con lugares diseñados } \\
\text { para los mismos }\end{array}$ & Claridad de espacios \\
\hline $\begin{array}{l}\text { Arraigo de los habitantes respecto a su entorno } \\
\text { urbano }\end{array}$ & Antigüedad de los vecinos \\
\hline Elementos de Fragmentación, discontinuidades & Muros, vallas, calles fondo de saco \\
\hline
\end{tabular}

8. ACTIVIDAD / USOS

\begin{tabular}{l|l}
\hline 8.- Vida urbana. Actividad/Usos: & (de AL21SE) \\
\hline Actividad / Residencia & área (m2) uso residencial/ área (m2) total *100 \\
Locales & DESEABLE: $60 \%$ \\
& área (m2) uso servicios/ área (m2) total *100 \\
& DESEABLE: $20 \%$ \\
& (de PEISAU2008SE) \\
& RESERVA ÓPTIMA DE USO COMERCIAL EN PLANTA BAJA > 80\% \\
& ACTIVIDADES DE PROXIMIDAD: Mínimo el 10\% de aprovechamiento lucrativo \\
& no residencial \\
\hline Actividad comercial: vinculación a las actividades & (de PEISAU2008SE) \\
de los locales comerciales 0 equipamientos (mer- & DIMENSIONADO DE LOS LOCALES COMERCIALES EN PLANTA BAJA \\
cadillo, exposiciones, et.c) & SUPERFICIES ÚTILES A PARTIR DE 50 M² Y HASTA UN MÁXIMO DE 200 M². \\
& APLICACIÓN PARA EL 80\% DE LOS LOCALES UBICADOS EN EDIFICIOS CON US0 \\
& PRINCIPAL RESIDENCIAL. \\
& Fórmula de cálculo: \\
& Número de locales con superficie comprendida entre 50 y 200 m² / número de \\
& locales totales * 100 \\
& Con el objetivo de establecer un número de locales mínimos en los nuevos de- \\
& sarrollos edificados y acoger una determinada densidad de actividades, el 80 \\
& $\%$ de los locales en planta baja deben incluir áreas comprendidas entre los 50 \\
& y 200 m² \\
\hline Actividades @, Cultura & (de PEISAU2008SE) \\
& Actividades y servicios avanzados (Tecnologías de la Información y las \\
& Comunicaciones) \\
\hline
\end{tabular}




\begin{tabular}{|c|c|}
\hline $\begin{array}{l}\text { Cohesión social y Cultura } \\
\text { Acceso a equipamientos y servicios básicos, so- } \\
\text { ciales y comunitarios. } \\
\text { Oportunidades para la interacción social a través } \\
\text { de la inclusión de los servicios sociales y comu- } \\
\text { nitarios }\end{array}$ & $\begin{array}{l}\text { (de PEISAU2008SE) } \\
\text { Distancia óptima a pie de los equipamientos del proximidad: } \\
\text { - Mercado municipal: }<10 \text { minutos } \\
\text { - Centro de salud público: }<10 \text { minutos } \\
\text { - Escuela infantil: }<5 \text { minutos } \\
\text { - Centro educación primaria: }<5 \text { m minutos } \\
\text { - Centro educación secundaria: }<10 \text { minutos } \\
\text { - Centro cívico asociativo: }<5 \text { minutos } \\
\text { - Biblioteca/centro cultural: }<10 \text { minutos } \\
\text { - Espacio deportivo de barrio: }<10 \text { minutos } \\
\text { - Centro de servicio social comunitario: }<10 \text { minutos }\end{array}$ \\
\hline $\begin{array}{l}\text { Vinculación de las actividades de los locales co- } \\
\text { merciales o equipamientos al espacio }\end{array}$ & $\mathrm{N}^{0}$ actividades en el espacio público: mercadillo, exposiciones, etc. \\
\hline $\begin{array}{l}\text { Cercanía y conexión a un espacio libre de escala } \\
\text { metropolitana }\end{array}$ & $\begin{array}{l}\text { Óptimo: } 10 \text { a pie, } 4 \text { en bici } \\
\text { Medio: } 15 \text { minutos a pie y } 7 \text { en bici }\end{array}$ \\
\hline
\end{tabular}

\section{MOBILIARIO URBANO}

\begin{tabular}{l|l}
\hline \multicolumn{2}{l}{ 9.- Mobiliario urbano: } \\
\hline $\begin{array}{l}\text { Mobiliario urbano para la habitabilidad, accesibi- } \\
\text { lidad e inclusión social zona de estacionamiento } \\
\text { especial, intercambiadores, etc. }\end{array}$ & $\begin{array}{l}\text { Bancos: Distancia inferior a } 250 \text { metros } \\
\mathrm{N}^{0} \text { fuentes: Distancia inferior a } 250 \text { metros } \\
\text { Juegos de niños } / \mathrm{n}^{\circ} \text { habitantes (densidad residencial) } \\
\text { Servicios públicos: paradas bici y bus, cabinas, contenedores } \\
\text { Elementos de accesibilidad (braille, barandillas, etc.) } \\
\text { Zonas de estacionamiento especial, } \\
\text { Baños públicos, }\end{array}$ \\
\hline TIC, eficiencia energética y lumínica. & Zona wifi, Elementos de sombra, lluminarias (eficiencia energética y lumínica). \\
\hline Ergonomía y habitabilidad térmica & Ergonomía y habitabilidad térmica de los materiales (propios del contexto) \\
\hline
\end{tabular}

\section{GESTIÓIN Y PARTICIPACIÓN CIUDADANAS / MANTENIMIENTO Y AUTONOMÍA}

\begin{tabular}{l|l}
\hline \multicolumn{2}{l}{ 10.- Gestión y Participación ciudadana: } \\
\hline Empoderamiento y representación ciudadana & $\begin{array}{l}\mathrm{N}^{0} \text { de Asociaciones vecinales, culturales, equipamientos para la convivencia, } \\
\text { ateneos, etc. } \\
\text { Implicación de los vecinos en el diseño }\end{array}$ \\
\hline Identidad, vigilancia natural & $\begin{array}{l}\text { Niveles de ocupación del lugar. Temporalización: } N^{0} \text { de horas de actividad } \\
\text { urbana. }\end{array}$ \\
\hline $\begin{array}{l}\text { Gestión y mantenimiento adecuada del espacio } \\
\text { urbano }\end{array}$ & $\begin{array}{l}\mathrm{N}^{0} \text { de actividades ciudadanas vinculadas al buen uso y mantenimiento del } \\
\text { espacio: } \\
\text { rutas, deportes, huertos, y otras actividades vecinales en torno al espacio } \\
\text { público }\end{array}$ \\
\hline Favorecer a colectivos: niños, mayores y mujeres & \begin{tabular}{l} 
Horario de actividades compatibles e intergeneracionales \\
\hline
\end{tabular}
\end{tabular}

